NBER WORKING PAPER SERIES

\title{
COMMON SHOCKS IN STOCKS AND BONDS
}

\author{
Anna Cieslak \\ Hao Pang \\ Working Paper 28184 \\ http://www.nber.org/papers/w28184 \\ NATIONAL BUREAU OF ECONOMIC RESEARCH \\ 1050 Massachusetts Avenue \\ Cambridge, MA 02138 \\ December 2020
}

We thank Hengjie Ai, Jonas Arias, Ravi Bansal, Tim Bollerslev, Michael Boutros, Ian DewBecker, Morad Elsaify, Anastassia Fedyk, Rene Garcia, Jim Hamilton, Sam Hanson, Cam Harvey, Sydney Ludvigson, Monika Piazzesi, Carolin Pflueger, Guillaume Roussellet, Andreas Schrimpf, Ivan Shaliastovich, Dongho Song, Eric Swanson, Viktor Todorov, Christian Wolf, Yunmin Wu, Irina Zviadadze, as well as conference and seminar participants at the LBS Summer Symposium in Asset Pricing, ASSA CES meetings, NBER Asset Pricing Spring workshop, NBER Monetary Economics Summer Institute, Western Finance Association meetings, Queen Mary University London, Federal Reserve Board, McGill Desautels, AQR, Imperial College, EDHEC, Vienna Graduate School of Finance, Federal Reserve Bank of San Francisco, Boston College, University of Delaware, Sveriges Riksbank, Norges Bank, BI Norwegian Business School, University of Illinois at Urbana-Champaign, Q-Group, Duke Fuqua, and the Triangle Macro-Finance Workshop for helpful comments. The views expressed herein are those of the authors and do not necessarily reflect the views of the National Bureau of Economic Research.

NBER working papers are circulated for discussion and comment purposes. They have not been peer-reviewed or been subject to the review by the NBER Board of Directors that accompanies official NBER publications.

(C) 2020 by Anna Cieslak and Hao Pang. All rights reserved. Short sections of text, not to exceed two paragraphs, may be quoted without explicit permission provided that full credit, including (C) notice, is given to the source. 
Common Shocks in Stocks and Bonds

Anna Cieslak and Hao Pang

NBER Working Paper No. 28184

December 2020

JEL No. E43,E44,G12,G14

\title{
ABSTRACT
}

We propose an approach to identifying economic shocks (monetary, growth, and risk-premium news) from stock returns and Treasury yield changes, which allows us to study the drivers of asset prices at a daily frequency since the early 1980s. We apply the identification to examine investors' responses to news from the Fed and key macro announcements. We uncover two riskpremium shocks - time-varying compensation for discount-rate and cash-flow news-which have distinct effects on stocks and bonds. Since the mid-1990s, the Fed-induced reductions in both risk premium sources have generated high average stock returns but an ambiguous response in bonds on FOMC days.

\author{
Anna Cieslak \\ Fuqua School of Business \\ Duke University \\ P.O. Box 90120 \\ Durham, NC 27708 \\ and NBER \\ Anna.cieslak@duke.edu \\ Hao Pang \\ Duke University \\ 100 Fuqua Dr \\ Durham, NC 27708 \\ hao.pang@duke.edu
}




\section{Introduction}

What are the common economic shocks driving the aggregate stock market and the Treasury yield curve? More specifically, how important is news about monetary policy, news about economic fundamentals, and pure risk-premium shocks for determining the observed asset price dynamics? To answer these questions, we propose a framework to identify economic shocks from daily stock returns and Treasury yield changes. We impose intuitive identification, motivated by theory, to isolate four orthogonal shocks - growth news, monetary news, and two distinct risk-premium shocks - by exploiting their differential impacts on stocks and yields across maturities.

Our identification strategy involves two sets of restrictions: on the effect that different shocks have on the yield curve across maturities and on the comovement between stocks and yields. ${ }^{1}$ The cross-maturity restrictions serve to separate shocks driving short-rate expectations - monetary and growth news in our setting-from shocks to the risk premium. They derive from the fact that long-term yields are conditional expectations of average future short-term rates plus the risk premium. To the extent that shocks to short-rate expectations are mean-reverting (although can be persistent), they affect the short end of the yield curve more strongly than the long end. The strength of relative responses of yields at different maturities can thus be exploited to isolate the risk-premium shocks.

The restrictions on the stock-yield comovement further distill shocks to short-rate expectations into monetary and growth news and risk-premium shocks into an exposure that is common to stocks and bonds and a hedging component. Growth news reflects shocks to investors' cash-flow expectations. Good growth news raises both stock prices and yields. Monetary news, instead, captures pure discount-rate shocks via the current or expected risk-free rate. Good monetary news (monetary easing) raises stock prices but depresses yields. Importantly, we also uncover two riskpremium shocks - which we refer to as the common premium and the hedging premium - that differ in the direction of the comovement between stocks and yields that they generate. Positive common premium news raises both equity and bond risk premium, reflecting the fact that stocks and bonds are both exposed to pure discount-rate risk. On the contrary, positive hedging premium news raises the risk premium on stocks but lowers it on bonds because bonds provide a hedge for cash-flow

\footnotetext{
${ }^{1}$ We refer to the direction of the comovement of stock returns with yield changes rather than with bond returns. Negative comovement of stock returns with yield changes implies a positive comovement of stock and bond returns.
} 
risk in stocks. Thus, both types of risk-premium news work to affect stock prices in the same way (positive premium shocks lower stock prices), but they have the opposite effect on bonds (a positive common premium shock lowers bond prices and raises yields, while a positive hedging premium shock does the opposite).

We implement the above ideas via sign restrictions drawing on a large structural vector autoregressions (VAR) literature. ${ }^{2}$ Sign restrictions allow us to transform reduced-form innovations in asset prices into shocks that have a particular economic interpretation without imposing a parametric structure of a fully-specified asset pricing model. As such, our approach combines the finance perspective following Campbell and Ammer (1993) that studies cash-flow and discount-rate news as drivers of asset prices with the macro view that focuses on structural disturbances as pioneered by Sims (1980). The VAR framework in Campbell and Ammer (1993) does not assume economic structure beyond a dynamic accounting identity. While we do not require a fully specified model, we impose restrictions on the VAR that are compatible with how stocks and bonds respond to economic shocks in a range of macro-finance models. The flexibility of not relying on a fully specified model comes with both advantages and costs. With less structure, the approach is relatively more robust to model misspecification. It can also be implemented at high frequencies using information in asset prices alone. At the same time, we do not pin down the exact economic mechanism or microfoundations. For example, the risk-premium shocks that we identify can arise as a result of time-varying risk aversion (as in the habit model) or time-varying uncertainty (as in the long-run risk model), or both.

We apply the identification to explore two sets of questions. First, focusing on some of the most important economic events, we dissect the content of news coming out from the Fed and on days with key macroeconomic announcements. Second, we analyze more broadly how different shocks have shaped the dynamics of stocks and bonds since the early 1980s.

In our first application, we study the channels through which the Fed affects asset prices and the economy. The identified shocks map onto three main channels of policy transmission debated in the literature: the conventional monetary news channel via the risk-free rate, the growth news channel (the so-called Fed information effect), and the risk-premium channel, allowing us to quantify

\footnotetext{
${ }^{2}$ See e.g., Faust (1998), Faust et al. (2004), Uhlig (2005), Rubio-Ramírez et al. (2010), Arias et al. (2019), Ludvigson et al. (2020), as well as Fry and Pagan (2011) and Kilian and Lütkepohl (2017) for reviews of this literature.
} 
their relative strengths. ${ }^{3}$ We document a pronounced effect of risk-premium shocks on stocks and bonds on days containing information from the Fed. From 1994 to 2017, the average close-to-close stock market return on Federal Open Market Committee (FOMC) announcement days is nearly 30 basis points (bps) higher relative to all other days, but the ten-year Treasury bond return is not significantly changed, consistent with Lucca and Moench (2015) estimates for the 1994-2011 sample. We show that the seemingly puzzling behavior of bonds vis-à-vis stocks is predominantly driven by risk-premium news. Specifically, from the mid-1990s, reductions in both sources of risk premium (the common and hedging premium) contribute to raising stock prices on FOMC days. Risk-premium shocks generate nearly $70 \%$ of the average FOMC-day increase in stock returns, while monetary easing shocks account for an additional 25\%. Importantly, individual shocks also have an economically significant impact on bonds. Reductions in the common premium increase the FOMC-day return on the ten-year Treasury by 8 bps, and monetary easing shocks add another 3 bps. However, those gains are offset by a decline in the value of the hedging premium, which depresses bond prices, making the overall bond market response economically small and statistically insignificant.

The finding that the risk-premium reduction is the primary reason for high stock returns on FOMC days is consistent with the interpretation of Cieslak et al. (2019, CMVJ). CMVJ document that the FOMC-day returns are part of a regular pattern of high average stock returns earned in "even weeks" in FOMC cycle time. We find that while even weeks are associated with more news of policy accommodation, the impact of risk-premium shocks is about 3.5 times stronger than that of monetary shocks via the short rate.

The ability to identify news on any day matters for assessing the overall effect that different shocks have on asset prices. The case of monetary policy transmission illustrates the importance of this point. Identification of monetary shocks in the literature typically relies on the timing of the Fed announcements and the assumption that those announcements only reveal monetary policy news, i.e., exogenous shocks to the risk-free rate caused by the Fed. The practical difficulties with this approach are two-fold: First, monetary news can come out outside of the scheduled Fed events. Second, the Fed's communication can cause investors to update beliefs about the state of

\footnotetext{
${ }^{3}$ The information content of central bank communication is the subject of a growing literature, e.g., Romer and Romer (2000), Campbell et al. (2012), Hanson and Stein (2015), Nakamura and Steinsson (2018), Swanson (2018), Cieslak and Schrimpf (2019), Jarocinski and Karadi (2020).
} 
the economy or uncertainty, rather than just about the Fed's preference for the path of the short rate. Our approach circumvents issues that emerge in identification via the timing of events and, instead, extracts news from asset prices using economically motivated restrictions that should hold on any day. We show that monetary policy surprises obtained with event-timing restrictions (e.g., Gürkaynak et al., 2005b) are a combination of economically distinct shocks that we identify.

Beyond the Fed-induced news, we study the content of the non-farm payroll releases to illustrate a similarly multidimensional nature of macroeconomic announcements. Our results show that non-farm payroll releases induce significant updates to investors' expectations about the stance of monetary policy. Specifically, while during contractions, investors perceive non-farm payroll numbers as revealing information about economic growth, in expansions, they view them primarily as news about the path of the risk-free rate. This fact accounts for the stock market frequently rising on bad employment news in good times, as initially highlighted by Boyd et al. (2005).

Finally, we analyze the overall importance of different shocks for the dynamics of stocks and bonds. Using variance decompositions of daily yield changes and stock returns, we show that from 1983 to 2017 , about $80 \%$ of the variance of the two-year yield changes is driven by monetary and growth news, in similar shares each. These proportions reverse for the ten-year yield changes for which $80 \%$ of the variance is explained by premium shocks, split into $45 \%$ and $35 \%$ contributions of the common and hedging premium, respectively. The risk-premium news also constitutes the main portion (nearly 60\%) of the variation in stock returns, while growth news accounts for about $25 \%$ and monetary news for less than $20 \%$ of the stock return variance. Analyzing the sources of the time-varying comovement between stocks and yields, we attribute the change in stock-yield correlations from negative to positive in the late 1990s to a diminished role of the common premium and monetary shocks (both of which drive stocks and yields in opposite directions), and increased importance of growth and, in particular, hedging premium shocks (both of which drive stocks and yields in the same direction).

We validate our identification in several ways. We tie it to external variables that one expects to be sensitive to economic shocks we aim to recover. We show that survey expectations of macroeconomic variables at different horizons display economically meaningful responses to the identified shocks. We also verify that our risk-premium shocks relate with the expected signs to a variety of measures of bond and equity premium in the literature. Across the different measures, we consistently find that 
the equity risk premium proxies are positively related to both the hedging and common premium, while bond risk premium proxies are positively related to the common premium but negatively to the hedging premium. Our identification does not separately identify shocks to expected inflation. We draw on the literature and provide empirical evidence to argue that due to the very persistent nature of inflation expectations, expected inflation shocks have a minimal impact on daily asset returns and, hence, on our identification.

Related literature. We build on a large body of work that studies the comovement between stocks and bonds. Andersen et al. (2007) and Connolly et al. (2005) document that the comovement changes sign over time. A number of authors develop macro-finance models to investigate the joint pricing of stocks and bonds. ${ }^{4}$ Baele et al. (2010) show that exposures to observable macroeconomic variables explain a relatively small fraction of stock-bond correlations over time and suggest that risk premia drive a significant part of the comovement. Campbell et al. (2020) emphasize the role of risk premia in providing a quantitative explanation of the stock-bond comovement within a consumption-based New Keynesian model with habit. Duffee (2018a) argues empirically that the comovement cannot be rationalized by the time-varying covariances of shocks to expectations of growth and inflation. We rely on these insights to propose a set of economic shocks to investors' beliefs about fundamentals, the path of monetary policy, and shocks to risk premium and isolate their effects on stocks and yields. In contrast to much of the literature, our approach does not rely on a specific parametric model. We instead impose restrictions on innovations in asset prices that summarize a range of different models to identify shocks with a particular economic interpretation.

Our results highlight the importance of a two-factor structure in risk premia. The low correlations between various empirical measures of the time variation in bond and equity premia point to the challenge of explaining the risk-premium dynamics with a single state variable. Countercyclical variation typically found in the equity risk premium is less clear for bonds, whose expected returns tend to vary at a frequency higher than the business cycle (e.g., Cieslak and Povala, 2015). Accordingly, successful predictors of bond returns have a low predictive power for stock returns and vice versa (e.g., Cochrane and Piazzesi, 2005). We find that accounting for two sources of risk premium shocks and allowing for a differential exposure of stocks and bonds to those shocks is crucial for understanding the joint drivers of stock and bond risk premium.

\footnotetext{
${ }^{4}$ See Bekaert et al. (2009), Bekaert et al. (2010b), Burkhardt and Hasseltoft (2012), Campbell et al. (2017), Campbell et al. (2020), David and Veronesi (2013), Koijen et al. (2017), Lettau and Wachter (2011), Song (2017).
} 
A growing literature uses the comovement of stocks and yields as an identification tool to distinguish types of news (e.g., Matheson and Stavrev (2014), Cieslak and Schrimpf (2019), and Jarocinski and Karadi (2020)). Both Cieslak and Schrimpf (2019) and Jarocinski and Karadi (2020) concentrate on analyzing central bank communication in narrow event windows. We contribute to this literature in several ways. As the main innovation, we exploit the cross-section of yields to isolate the riskpremium shocks in a sign-restricted VAR framework. Jarocinski and Karadi (2020) and Matheson and Stavrev (2014) focus on a single yield maturity (a three-month Fed fund futures rate and a ten-year yield, respectively) without taking a stance on the variation in the risk premia. Cieslak and Schrimpf (2019) make a step toward identifying risk-premium shocks, but do not distinguish between the common and the hedging premium. Their primary analysis exploits the high-frequency realized covariance structure between stocks and yields to classify the news content of different modes of communication used by four main central banks. Our approach is broader in that it allows us to extract economic shocks driving US stocks and bonds on any day going back to the 1980s.

The paper is structured as follows. Section 2 contains the conceptual framework and discusses the identification approach. Section 3 lays out the empirical implementation. Section 4 explores the news coming out on FOMC days, over the FOMC cycle, and around non-farm payroll announcements. Section 5 analyzes the contributions of different shocks to the overall variation in stocks and yields and studies the persistence of news effects on asset prices. Section 6 validates the interpretation of the identified shocks and provides a stylized model to motivate our identification. Section 7 concludes. Internet Appendix contains supporting details, additional results, and robustness checks.

\section{Conceptual framework}

\subsection{A structural VAR interpretation of asset pricing models}

Asset prices (bond yields, log price-dividend ratios) are often modelled as affine functions of the state variables. Let $Y_{t}$ be the vector of asset prices, and $F_{t}$ be the vector of state variables. For simplicity, we assume that $Y_{t}$ contains as many elements as there are state variables $F_{t}, k$ :

$$
Y_{t}=a+A F_{t}
$$


where $a_{(k \times 1)}$ and $A_{(k \times k)}$ are functions of parameters that characterize the dynamics of the economy and investors' preferences. Suppose that $Y_{t}$ evolves according to a VAR

$$
Y_{t}=\mu_{Y}+\Psi(L) Y_{t}+u_{t}
$$

where $\Psi(L)$ is the polynomial in the lag operator $L, \Psi(L)=\sum_{i=1}^{p} \Psi_{i} L^{i}$, and innovations $u_{t}$ have a variance-covariance matrix $\operatorname{Var}\left(u_{t}\right)=\Omega_{u}$. When matrix $A$ is invertible, substituting (1) into (2) implies the dynamics for the state variables, $F_{t}$,

$$
F_{t}=\mu_{F}+\Phi(L) F_{t}+\nu_{t}
$$

where $\mu_{F}=A^{-1}\left(\mu_{Y}-(I-\Psi(L)) a\right)$, with $I$ identity matrix, $\Phi_{i}=A^{-1} \Psi_{i} A$, and $\nu_{t}=A^{-1} u_{t}$. We assume that shocks to the state variables are mutually uncorrelated, $\nu_{t}=\Sigma_{F} \omega_{t}$ where $\Sigma_{F}$ is a diagonal matrix and $\omega_{t}$ is unit-variance, $\operatorname{Var}\left(\omega_{t}\right)=I$. Innovations to asset prices, $Y_{t}-E_{t-1}\left(Y_{t}\right)=$ $u_{t}$, are

$$
u_{t}=\tilde{A} \omega_{t}, \quad \text { with } \quad \tilde{A}=A \Sigma_{F} .
$$

Asset prices are available at high frequencies, and innovations $u_{t}$ are simply residuals from the reduced-form VAR in equation (2). However, state variables describing investors' beliefs and risk premia are, in general, not directly observed even at lower frequencies. Therefore, identification of the $\tilde{A}$ matrix, and hence of shocks $\omega_{t}$, requires additional assumptions. The state variables $F_{t}$ we are interested in encapsulate investors' beliefs about the economic fundamentals and the path of monetary policy, as well as drivers of time-variation in the risk premia.

We refer to equation (3) as the "structural form" to highlight that shocks we seek to identify are counterparts to exogenous shocks that appear in asset pricing and macro-finance models. In this sense, our notion of shocks borrows from the structural VAR literature. In a recent review, Ramey (2016) defines structural shocks as exogenous forces in a model, uncorrelated with other exogenous shocks, and representing unanticipated movements in exogenous variables or news about future movements in those variables. This definition is different from the decomposition of asset prices into cash-flow and discount-rate news in the tradition of Campbell and Ammer (1993), which does not produce orthogonal shocks because the underlying VAR framework is unrestricted. As highlighted by Campbell and Ammer (1993), correlations introduce ambiguity in interpretation of discount-rate and cash-flow news. However, standard orthogonalization approaches such as the 
Cholesky scheme do not apply in the context of asset prices because it is not possible to economically justify any given VAR ordering.

We achieve orthogonality by imposing additional structure on the $\tilde{A}$ matrix which summarizes equilibrium relationships in the economy connecting asset prices and shocks. Underlying this approach is the idea that leading asset pricing and macro-finance models embed exogenous shocks to the endowment process, risk premia (due to shocks to the risk aversion or uncertainty), and to the short-term interest rate. Such shocks have a structural interpretation in that they represent primitive sources of risk in a model and are mutually uncorrelated. For example, shocks to risk aversion in the habit model or volatility shocks in the long-run risk model generate part of variation in risk premia that is independent from other fundamentals. Similarly, shocks to the Taylor rule in New-Keynesian models (monetary shocks) drive exogenous variation in the short-term interest rate. Our goal is to identify such shocks from asset prices by imposing a minimal structure.

Several additional points are worth highlighting. First, on any given day, innovations in asset prices $u_{t}$ are a linear combination of all structural shocks in $\omega_{t}$. This allows us to dissect the news coming out on a daily basis, including on days with the Fed or macroeconomic announcements, without zeroing out any of the shocks by assumption. Second, $\omega_{t}$ shocks are only orthogonal contemporaneously (on any given day), but we do not constrain how shocks affect asset prices and other state variables in future periods. That is, we do not exclude situations whereby, say, a positive growth shock leads to a tighter policy rate in subsequent periods or a negative growth shock raises risk premia going forward. Similarly, on any given day, we may find that there is an exogenous monetary shock or a risk-aversion shock and those shocks can affect other state variables going forward. Econometrically, this is captured by the fact that the VAR feedback matrix in (2) and the impulse responses are not constrained in our approach. Third, while we do not explicitly model stochastic volatility, our empirical approach allows us to recover shocks to time-varying second moments to the extent that such shocks affect asset prices via risk premia. Therefore, we implicity assume that uncertainty is an element of $F_{t}$, and treat $\Sigma_{F}$ as constant. ${ }^{5}$

\footnotetext{
${ }^{5}$ We discuss the implications of the time-varying volatility of structural shocks by allowing $\Sigma_{F}$ to change over time in Appendix B, and argue that it does not have an effect on the historical decomposition of asset returns into contributions of structural shocks.
} 


\subsection{Recovering economic shocks from Treasury yields and the stock market}

Rather than using a specific parametric model that ties asset prices to state variables through a single $\tilde{A}$ matrix, we impose sign restrictions on the responses of asset prices to shocks that summarize predictions across different models. This approach leads to a set (as opposed to a point) identification of $\tilde{A}$, but it also involves weaker assumptions about the detailed structure of the economy, such as the form of stochastic discount factor or the estimates of the state dynamics. Each matrix $\tilde{A}$ from the identified set can therefore be viewed as representing equilibrium relations consistent with a particular model. ${ }^{6}$

Let $\omega_{t}=\left(\omega_{t}^{g}, \omega_{t}^{m}, \omega_{t}^{p+}, \omega_{t}^{p-}\right)^{\prime}$ denote shocks to investor growth expectations $\left(\omega_{t}^{g}\right)$, shocks to expectations of monetary policy path $\left(\omega_{t}^{m}\right)$, and two pure risk-premium shocks, the common and the hedging premium $\left(\omega_{t}^{p-}, \omega_{t}^{p+}\right)$. We impose restrictions on how those shocks impact the aggregate stock market and the nominal Treasury yield curve. Let $Y_{t}$ contain three yields of different maturities and the price/dividend ratio, $Y_{t}=\left(y_{t}^{\left(n_{1}\right)}, y_{t}^{\left(n_{2}\right)}, y_{t}^{\left(n_{3}\right)}, p d_{t}\right)$, where $y_{t}^{\left(n_{i}\right)}$ is continuously compounded yield with an $n_{i}$-year maturity and $p d_{t}$ is the log price-dividend ratio. Given $Y_{t}-$ $E_{t-1}\left(Y_{t}\right)=\tilde{A} \omega_{t}$, we recover $\omega_{t}$ from innovations in $Y_{t}$ by identifying $\tilde{A}$. The identification exploits two types of conditions: $(i)$ how a shock propagates through the yield curve across maturities, and (ii) the direction with which it impacts the stock market and the yield curve.

We discuss and motivate the restrictions next, and provide their concise summary in Appendix A. In Section 6.3, we illustrate the effect of $\omega$ shocks within a simple affine macro-finance model of stocks and yields.

\subsubsection{Cross-maturity restrictions}

We use restrictions across maturities in the Treasury yield curve to separate shocks to short-rate expectations from shocks to the risk premium. Specifically, we assume that the impact of short-rate expectations shocks (growth and monetary news, $\omega^{g}$ and $\omega^{m}$ ) across the yield curve decays with yield maturity, while that of risk-premium shocks (hedging and common premium news, $\omega^{p+}$ and $\omega^{p-}$ ) increases with maturity.

\footnotetext{
${ }^{6}$ The robustness aspect of identification via sign restrictions is emphasized by the work of, e.g., Dedola and Neri (2007), Peersman and Straub (2009), and Canova and Paustian (2011). This literature uses sign restrictions as means to acknowledge the uncertainty over precise parameter values of the underlying models and to ensure robustness to small model perturbations.
} 
The motivation for the cross-maturity restrictions comes from a large literature on affine term structure models and from empirical evidence on the properties of the bond risk premium. Starting from the basic yield curve identity, the current $n$-period log nominal yield $y_{t}^{(n)}$ on a Treasury bond is a sum of investors' expectations about the average future short rate $y_{t}^{(1)}$ (the expectations hypothesis (EH) term) and about the average one-period excess bond returns to be earned over the life of the bond (the term premium):

$$
y_{t}^{(n)}=\underbrace{\frac{1}{n} \sum_{k=0}^{n-1} E_{t}\left(y_{t+k}^{(1)}\right)}_{\text {EH term }}+\underbrace{\frac{1}{n} \sum_{k=0}^{n-2} E_{t}\left(r x_{t+k+1}^{n-k}\right)}_{\text {term premium }} .
$$

For illustration, we consider a stylized example of an affine model with two independent state variables: a short-rate factor $i_{t}$, with $y_{t}^{(1)}=i_{t}$, and a market price-of-risk factor $x_{t}$, where both state variables follow independent $\mathrm{AR}(1)$ processes with persistence parameters $\phi_{i}$ and $\phi_{x}$, respectively. Let us assume that only short-rate shocks to $i_{t}$ are priced by investors, and the exposure to those shocks earns a time-varying risk premium driven by $x_{t}$. In this way, $i_{t}$ determines the EH component and $x_{t}$ determines the term premium component in the yield curve. This setting is sufficient to illustrate the mechanism that arises in more complicated and empirically successful models of the term structure. ${ }^{7}$ We discuss the main intuition below and relegate the details to Appendix C.1.

Under the above assumptions, the variation in long-term yields due to short-rate expectations (EH term) is $y_{t}^{(n), E H}=$ const. $+\frac{1}{n} \frac{1-\phi_{i}^{n}}{1-\phi_{i}} i_{t}$. If $\left|\phi_{i}\right|<1$, the impact of shocks to the short rate declines with maturity $n$, as $\frac{1}{n} \frac{1-\phi_{i}^{n}}{1-\phi_{i}}<1$ declines with $n$. While in practice the short-rate dynamics are more complex than the simple AR(1) example, the intuition extends to a multivariate case (see Appendix C.2). Non-standard expectations formation (e.g., expectations stickiness) can generate non-monotonic responses of yields to short-rate shocks across maturities. Still, as long as the short rate is stationary, the effect of short-rate shocks eventually dies out with maturity.

The effect of risk-premium shocks is negligible at the short-end of the term structure. Intuitively, short-term bonds are not very risky as the uncertainty about the short rate-whose shocks are the source of priced risk - in the near-term is small. However, holding longer-term bonds exposes investors to all future short-rate shocks over the life of the bond. As this effect accumulates, so

\footnotetext{
${ }^{7}$ Models that introduce separate state variables driving short-rate expectations and risk premia are common in the literature, e.g., Cochrane and Piazzesi (2008), Bansal and Shaliastovich (2013), Campbell et al. (2017), Campbell et al. (2020), Lettau and Wachter (2011), Cieslak and Povala (2015). Additionally, Cieslak and Povala (2015) show empirically that the variation in bond risk premium is uncorrelated with the variation in short-rate expectations.
} 
does the impact of time-varying risk premium $x_{t}$ on yields across maturities. Additionally, the accumulating effect of risk premium shocks across maturities strengthens when short-rate shocks are longer lived (higher persistence $\phi_{i}$ ). The result does not hinge upon extremely persistent riskpremium dynamics. ${ }^{8}$

The intuition from the two-factor example is consistent with estimates in the literature based on models that impose different economic assumptions on the short-rate dynamics and risk prices (e.g., Bansal and Shaliastovich (2013), Greenwood and Vayanos (2014), Hanson and Stein (2015)) as well as with reduced-form no-arbitrage models of the yield curve (e.g., Cieslak and Povala (2015, 2016), Kim and Wright (2005)). Considering yields with maturity up to twenty years, Cieslak and Povala (2015) document that the effect of shocks to short-rate expectations declines in maturity while that of risk-premium shocks increases in maturity. Their estimates suggest that a one-standard deviation risk-premium shock moves the ten-year yield more than twice as strongly as it moves the two-year yield. Duffee (2018b) reports similar cross-sectional effects based on several different specifications of a reduced-form VAR model.

\subsubsection{Shock-specific restrictions}

Next, we discuss the restrictions on each of the four shocks in $\omega_{t}=\left(\omega_{t}^{g}, \omega_{t}^{m}, \omega_{t}^{p+}, \omega_{t}^{p-}\right)^{\prime}$.

Shocks to growth expectations, $\omega^{g}$. A positive shock to growth expectations raises stock prices and bond yields, and impacts yields at short-to-intermediate maturities more than at long maturities.

We define growth news as a shock to investors' expectations about the growth rate of fundamentals (cash flows) in the economy. Such a shock can affect stock prices (price-dividend or price-consumption ratios) directly through cash-flow news channel but also indirectly through the discount-rate news channel because the risk-free short rate depends on growth expectations. Whether positive growth news raises or lowers stock prices depends on the relative strength of the two channels. In consumption-based asset pricing models such as the long-run risk model, positive growth news raises stock prices when the intertemporal substitution effect dominates the wealth effect, i.e., the EIS is greater than one (e.g., Bansal and Yaron, 2004). In a model with a forward-

\footnotetext{
${ }^{8}$ Appendix C.1 shows that the effect of risk-premium shocks on yields across maturities depends both on the persistence of shocks that are priced (short-rate shocks) and the persistence of shocks driving the time-variation in the risk-premium itself. The increasing impact of risk-premium shocks across maturities is generally stronger if both sources of shocks are relatively long-lived.
} 
looking Taylor rule, the cash-flow effect dominates if the Fed tightens the short rate less than one-for-one with growth expectations (see Section 6.3). Those models predict that growth shocks move stocks and yields in the same direction. In the cross-section of yields, we expect the effect of growth news to be more pronounced at short-to-intermediate maturities than at long maturities, reflecting the fact that growth shocks affect short-rate expectations and are mean-reverting, albeit can be persistent. ${ }^{9}$

To further motivate the growth news restrictions, we project monthly S\&P 500 index returns and zero-coupon yield changes over the 1983-2017 sample on contemporaneous updates to real GDP growth forecast from the monthly Blue Chip Economic Indicators (BCEI) survey. The results strongly support the growth restrictions. Appendix D contains details of these regressions.

Monetary shocks, $\omega^{m}$. A positive monetary shock (tightening) depresses stock prices and raises yields. The effect on yields declines in strength with yield maturity.

We define the monetary shock as an exogenous shock to the short-term risk-free rate, or its expected path, that is orthogonal to other state variables driving the short rate. The literature typically interprets monetary shocks as innovations to the Taylor rule, that is, deviations from the systematic component of the policy reaction function (see Ramey (2016) for an overview). The identification of monetary shocks in empirical applications exploits high-frequency movements of short-term interest rates in a narrow window around FOMC announcements. Our definition of monetary shocks is broader than that because it assumes that a pure risk-free rate shock can happen on any day. This assumption is motivated by the evidence that news from the Fed comes out on a continuous basis between the FOMC meetings (Cieslak et al., 2019).

The monetary restriction above reflects a discount-rate effect: A drop in the risk-free component of the discount rate pushes stock and bond prices higher on impact. This assumption is supported by the findings of Rigobon and Sack (2004) who show that a surprise increase in short-term interest rate leads to a decline in stock prices and to an upward shift in the yield curve that becomes smaller

\footnotetext{
${ }^{9}$ Such a maturity pattern is documented by a number of empirical studies (e.g., Balduzzi et al., 2001, Fleming and Remolona, 2001, Gürkaynak et al., 2018, 2005b). The results in Balduzzi et al. (2001) are reported for bond returns (rather than yield changes) and need to be divided by the negative of duration to be comparable with other studies. The effect of real-activity news on the yield curve is typically found to be hump-shaped, declining beyond maturities of two-to-three-years. The hump shape is consistent with models that have backward-looking components, for example, as generated by sticky expectations where agents do not update their beliefs immediately, but do eventually. In our empirical application, we do not take a stance on the hump shape, but we do require that growth news affects the ten-year yield less than the two- and five-year yields, in line with empirical evidence.
} 
at longer maturities. In the cross-section of yields, the response of the two-year yield is typically estimated to be about two-to-three times as large as the response of the ten-year yield. ${ }^{10}$ While there is a debate as to how persistent monetary shocks are, the fact that their effect subsides with maturity holds across different samples and methodologies. Indeed, in macro models, conventional monetary shocks operate by affecting the real rate gap, i.e., the distance of the real federal funds rate from the equilibrium (or natural) real rate. As the gap mean-reverts, the effect of such shocks on yields declines with maturity.

Finally, we also identify two pure risk-premium shocks: the common premium and the hedging premium shocks.

Risk-premium shocks, $\omega^{p-}, \omega^{p+}$. The risk-premium shocks affect the longer end of the yield curve more strongly than the short end of the yield curve. The two shocks differ in the direction of the comovement between stocks and yields which they generate. Common premium shocks $\omega^{p-}$ (hedging premium shocks $\omega^{p+}$ ) induce a negative (positive) comovement between yield changes and stock returns.

The risk-premium shocks determine the time-varying component of risk premia in stocks and bonds that is uncorrelated with monetary and growth news. Such shocks can arise from shifts in the risk aversion as in habit models (e.g., Campbell et al., 2020), from shocks to macroeconomic uncertainty (e.g., Bansal and Shaliastovich, 2013), or can be interpreted more broadly as sentiment or riskappetite shocks (e.g., Lettau and Wachter, 2007, 2011). While we do not take a stance on the exact mechanism, ${ }^{11}$ we seek to account for the fact that risk premium news is to a large extent unexplained by shocks to expectations of fundamentals. However, because the orthogonality assumption holds only contemporaneously, we do not preclude situations whereby, say, a negative shock to economic growth expectations feeds into higher risk premium in subsequent periods.

The two-factor structure of risk premium is motivated by the fact that one can view the stock market claim as a long-term bond plus cash-flow risk. It is thus plausible that risk premium shocks

\footnotetext{
${ }^{10}$ See Poole et al. (2002), Gürkaynak et al. (2005a), Gürkaynak et al. (2005b), Campbell et al. (2012), Hanson and Stein (2015), Nakamura and Steinsson (2018). Appendix Table IA-9 reviews the results in this literature.

${ }^{11}$ We thank our referee for pointing out that to distinguish between the types of risk premium shocks (e.g., whether time-varying risk premia are driven by shocks to risk aversion or volatility), one could introduce further restrictions on the convexity of the yield curve. We remain agnostic about the specific drivers of the risk premium given that, as Campbell (2018) puts it, “(..) the literature has not yet reached consensus even on a reduced-form model with an exogenous SDF, still less a structural model that derives the SDF from economic fundamentals" (p.295).
} 
in stocks and bonds are not perfectly correlated. Specifically, one can think of the two sources of the risk premium shocks as: $(i)$ the discount-rate risk premium that drives the common component in compensation required by stock and bond investors due to both being exposed to pure discountrate shocks; and (ii) the cash-flow risk premium which drives stock and bond premium in opposite directions - increases premium on stocks but lowers premium on bonds - due to bonds providing a hedge against bad economic times (as real rates generally decline in bad times). The hedging premium thus reflects the "flight-to-safety" effect. Our model in Section 6.3 generates such a structure in risk premia by assuming that investors require separate time-varying market prices of risk for exposures to monetary shocks and growth shocks. ${ }^{12}$

\subsubsection{The role of expected inflation news}

Since the restrictions above do not recover shocks to expected inflation, it is natural to ask how those shocks could affect our identification. One perspective is that inflation is endogenous (e.g., Gallmeyer et al., 2007), in which case expected inflation news is a function of the structural shocks we identify. Another view is that expected inflation news is exogenous, in which case it can confound our identification of other shocks. In particular, given that expected inflation news is a shock to short-rate expectations, it could be subsumed by either monetary or growth shocks we recover. ${ }^{13}$

It is an empirical question how strong such confounding effects are. In practice, expected inflation shocks are likely to have a small effect on our identification in the post-1983 sample. The main reason is that inflation expectations shocks that are priced into the nominal yield curve are highly persistent with a very low conditional volatility, as investors update their beliefs about trend inflation slowly over time (e.g., Sargent, 1999). ${ }^{14}$ Thus, the contribution of expected inflation shocks to the high-frequency (daily in our application) variation in yields is small (Bekaert et al.,

\footnotetext{
${ }^{12}$ The mechanism is similar in spirit to the model of Bansal and Shaliastovich (2013). In their setting, distinct risk-premium shocks emanate from variation in the real and nominal uncertainty. Both uncertainties increase the equity risk premium but impact bonds with opposite signs: nominal (real) uncertainty raises (lowers) the Treasury premium. These effects are a result of combining recursive preference with the assumption that inflation expectations have real effect on growth (with higher inflation predicting lower growth).

${ }^{13}$ Recent models connect stock-yield comovement to cyclical properties of inflation by introducing regime shifts in the sign of the conditional covariance between shocks to expected inflation and expected growth (e.g., Campbell et al., 2020, Song, 2017). Countercyclical inflation news (high inflation in bad times) generates a negative stock-yield comovement, similar to monetary news in our setting. Procyclical inflation news (high inflation in good times), instead, leads to a positive stock-yield comovement, similar to growth news. The illustrative model in Appendix F discusses the different scenarios in more detail.

${ }^{14}$ The volatile component of inflation expectations is driven mainly by transitory shocks to food and energy prices. Appendix Figure IA-5 Panel B shows that from the mid-1980s this component mean reverts within just a couple of
} 
2010a, Cieslak and Povala, 2015). Using inflation surveys, Duffee (2018b) estimates that expected inflation news explains between $10 \%$ and $20 \%$ of quarterly innovations in yields, even when including the volatile inflation period of the 1970s and early 1980s. Extrapolating from these results suggests that shocks to expected inflation should have a small impact on day-to-day variation in asset prices. To further support these claims, we tie identified $\omega$ shocks to survey expectations of inflation in Section 6.1 and to the variation in the TIPS and inflation swaps in Appendix E.

\section{Empirical implementation}

\subsection{Data and sample description}

Daily nominal zero-coupon yields are from Gürkaynak et al. (2006) published on the Federal Reserve Board website. Stock market returns on the S\&P 500 index are from the WRDS. The focus on highly liquid assets, Treasuries and the aggregate stock market, allows us to recover shocks at a daily frequency and over a long period. ${ }^{15}$ Our main sample spans from 1983 to 2017. There is substantial evidence that the Federal Reserve changed its policy conduct in the early 1980s (e.g., Clarida et al., 2000), switching to an interest rate target (Thornton, 2006). Since we are interested in monetary shocks as one of the components, our empirical analysis focuses on the post-1983 period.

\subsection{Estimation approach}

We obtain reduced-form innovations from a $\operatorname{VAR}(1)$ estimated by OLS on daily yield changes $\Delta y_{t}^{(n)}$ and daily log stock returns $\Delta s_{t}, z_{t}=\left(\Delta y_{t}^{(2)}, \Delta y_{t}^{(5)}, \Delta y_{t}^{(10)}, \Delta s_{t}\right) .{ }^{16}$ For simplicity, we use as many

quarters. Given that the Fed focuses on longer-term trends in inflation, such transitory shocks to inflation have little bearing on interest rates, as shown by Stock and Watson (2011) and Ajello et al. (2020).

${ }^{15}$ The approach could be extended to other assets such as inflation-indexed bonds (TIPS) or credit spreads, but their use is constrained by the available data samples and liquidity considerations. A large literature documents significant liquidity premia in corporate bonds (e.g., Bao et al., 2011) and in TIPS (e.g., Andreasen et al., 2018, Pflueger and Viceira, 2016).

${ }^{16}$ The use of stock returns as opposed to changes in the log price-dividend ratio is inconsequential for our results. Using Campbell-Shiller linearization, return innovations are $\Delta s_{t+1}-E_{t}\left(\Delta s_{t+1}\right) \approx \kappa_{1}\left(p d_{t+1}-E_{t}\left(p d_{t+1}\right)\right)+\left(d_{t+1}-\right.$ $\left.E_{t}\left(d_{t+1}\right)\right)$. The first term, $\left(p d_{t+1}-E_{t}\left(p d_{t+1}\right)\right)$, captures shocks to the state variables we are interested in, while $\left(d_{t+1}-E_{t}\left(d_{t+1}\right)\right)$ captures shocks to the current realizations of log dividends. At the daily frequency, the noise stemming from the second term can be assumed negligible given the smooth dynamics of aggregate dividends. A regression of daily cum-dividend returns on daily capital gains in the S\&P 500 index has the slope coefficient of 1.006, the intercept of $-1 \mathrm{bps}$, and the $R^{2}=0.9989$. We verify that using either cum-dividend returns or capital gains leads to essentially identical identified shocks and stock return decompositions. 
observables as there are $\omega$ shocks. Since the yield curve is almost perfectly spanned by three factors, inclusion of more yields does not provide significant new information. Elements of $z_{t}$ are demeaned before estimating the VAR. The lag length of one is determined using the Bayesian information criterion (BIC). Including more lags does not materially change the identified shocks.

We follow the standard approach to shock identification in sign-restricted VARs (see Kilian and Lütkepohl (2017) for an overview). We start from the Cholesky decomposition of the variancecovariance matrix of reduced-form shocks $u_{t}, \Omega_{u}=P P^{\prime}$, where $P$ is a lower triangular matrix, $u_{t}=P \omega_{t}^{*}$, and $\omega_{t}^{*}$ denotes a set of uncorrelated shocks, $\operatorname{Var}\left(\omega_{t}^{*}\right)=I$. Shocks $\omega_{t}^{*}$ correspond to the recursive identification. In our application, those shocks do not have an economic interpretation as it is hard to defend any particular ordering of asset prices in the VAR. One can obtain observationally identical set of reduced-form shocks by finding an orthonormal rotation matrix $Q_{i}$ such that $Q_{i} Q_{i}^{\prime}=Q_{i}^{\prime} Q_{i}=I$,

$$
u_{t}=P Q_{i}^{\prime} Q_{i} w_{t}^{*}
$$

where $Q_{i} w_{t}^{*}$ is another candidate set of uncorrelated shocks corresponding to matrix $Q_{i}$. We generate rotation matrices $Q_{i}$ following the approach of Rubio-Ramírez et al. (2010) based on the QR matrix factorization. ${ }^{17}$ Denoting by $\mathcal{R}$ the set of rotation matrices for which $\tilde{A}\left(Q_{i}\right)=P Q_{i}^{\prime}$ satisfies the restrictions laid out in Section 2.2.2, for each $Q_{i} \in \mathcal{R}$ we have

$$
u_{t}=\tilde{A}\left(Q_{i}\right) \omega_{t}\left(Q_{i}\right) \quad \text { and } \quad \omega_{t}\left(Q_{i}\right)=Q_{i} \omega_{t}^{*}
$$

We store $i=\{1, \ldots, 1000\}$ valid solutions on which we base our subsequent analysis. By construction, $\omega_{t}$ shocks for each solution are normalized to have zero mean and unit standard deviation over the 1983-2017 sample.

\subsection{Properties of the identified set}

The identification approach above leads to model multiplicity, with each model corresponding to different $\omega_{t}\left(Q_{i}\right)$. Summary statistics, such as mean or median of $\omega_{t}\left(Q_{i}\right)$ for $Q_{i} \in \mathcal{R}$, mix different solutions and lack a structural interpretation. Therefore, we follow the approach of Fry and Pagan

\footnotetext{
${ }^{17}$ This amounts to drawing $Q_{i}$ from a uniform distribution over the space of orthogonal matrices. In the Bayesian context, Baumeister and Hamilton (2015) show that an uninformative prior over $Q$ can be informative for the posterior over the structural impact matrix and impulse responses in sign-restricted structural VARs. Here, we follow a frequentist approach similar to Ludvigson et al. (2019, 2020).
} 
(2005, 2011) of selecting the median target (MT) solution, for which instantaneous asset price responses to structural shocks are the closest to the median response. For each $Q_{i} \in \mathcal{R}$, we denote the vector of instantaneous responses as $\theta_{i}=\operatorname{vec}\left(\tilde{A}\left(Q_{i}\right)\right)$. We then standardize each solution, $\theta_{i}$, by subtracting the element-wise median and dividing by the standard deviation, both measured over the set of models that satisfy identification restrictions:

$$
\theta^{M T}=\min _{i}\left[\frac{\theta_{i}-\operatorname{median}\left(\theta_{i}\right)}{\operatorname{std}\left(\theta_{i}\right)}\right]^{\prime}\left[\frac{\theta_{i}-\operatorname{median}\left(\theta_{i}\right)}{\operatorname{std}\left(\theta_{i}\right)}\right] .
$$

To illustrate the dynamics of shocks over time, Figure 1 graphs their cumulative paths constructed as expanding-window sums of daily shocks. We superimpose paths from the MT solution with the median of cumulative shocks across all retained models. The two paths are closely overlapping and display intuitive business cycle properties. Economic downturns are generally associated with negative growth news, monetary easing news, and positive risk-premium news.

There are two sources of uncertainty in our estimates: model uncertainty associated with the set identification and estimation uncertainty stemming from the estimates of the reduced-form VAR parameters. As typical in set identified models, also in our setting the estimation uncertainty is negligible compared to the model uncertainty. We thus relegate the discussion of estimation uncertainty to Appendix G (see in particular Appendix Figure IA-4). As a basic check of how identified shocks differ across solutions, we analyze the correlations between MT shocks and shocks from all other retained models. For each of the four shocks, the median correlation of the MT with other solutions exceeds 0.91, suggesting that different solutions produce highly correlated shocks over time (see Appendix Figure IA-6). In subsequent empirical analysis, we rely on the MT solution as our main estimates and characterize the model uncertainty by reporting the distribution of estimates across all retained models as robustness.

One concern about our specification pertains to the constant conditional volatility in the VAR. With Gaussian shocks, we do not explicitly model the time-varying second moments in asset prices, and identify shocks to volatility only to the extent that they affect asset prices through risk premia. Intuitively, when the true model has time-varying volatility, the shocks we recover under the constant volatility assumption will not be iid, but will feature volatility clustering. To examine the stability of the identified shocks, we reestimate the model on subsamples, 1983-1997, 19982007, and 2008-2017. The first breakpoint in the late 1990s is when the stock-yield correlation 
changed sign from negative to positive; the second breakpoint at the end of 2007 accounts for the zero-lower-bound period. ${ }^{18}$ We find that shocks identified over those subsamples are highly correlated with the full-sample counterparts, and are situated closely on a 45-degree line against each other (Appendix Figure IA-7). In the following sections, we provide robustness analysis of our results to subsample estimates. Appendix B contains further discussion of the stability of our results in the presence of time-varying volatility, and argues that time-varying volatility does not affect historical decompositions of asset returns into contributions of structural shocks, which we discuss next.

[Figure 1 about here.]

\subsection{Historical decompositions of daily stock returns and yield changes}

Historical decompositions describe the contribution of a shock to stock returns and yield changes realized on any given day. We rely on historical decompositions to analyze the sources of asset price movement induced by key economic events.

One can represent each element of $z_{t}=\left(\Delta y_{t}^{(2)}, \Delta y_{t}^{(5)}, \Delta y_{t}^{(10)}, \Delta s_{t}\right)$ as a sum of initial condition $z_{1}$ and subsequent shocks:

$$
z_{t}=\Phi_{z}^{t-1} z_{1}+\sum_{k=0}^{t-2} \Phi_{z}^{k} \tilde{A} \omega_{t-k} \quad \text { for } \quad t>1 .
$$

We denote the contribution of $i$-th shock to $j$-th element of $z_{t}$ as $z_{t}^{j}\left(\omega^{i}\right)$ :

$$
z_{t}\left(\omega^{i}\right)=\sum_{k=0}^{t-2} \Phi_{z}^{k} \tilde{A} J_{i i} \omega_{t-k},
$$

where $J_{i i}$ is a square matrix with $(i, i)$-th element equal to one and zeros elsewhere. Summing across shocks, $\sum_{i} z_{t}^{j}\left(\omega^{i}\right)$, we recover the overall stock return or yield change on day $t$ (up to the initial condition). ${ }^{19}$

\footnotetext{
${ }^{18}$ While the zero-lower bound constrained the volatility at the very short-end of the yield curve, the two-year yield (the shortest maturity we use) remained sensitive to news in that period (Swanson and Williams, 2014).

${ }^{19}$ The initial condition $z_{1}$ has a negligible effect that dies out very rapidly because daily stock returns and yield changes are not highly autocorrelated. Since vector $z_{t}$ is demeaned, the historical decompositions describe how much each shock pushes $z_{t}$ away from the unconditional mean of zero.
} 


\section{Dissecting asset price responses to Fed-induced and macro news}

We now turn to the main empirical application of our approach. Given that the identified shocks are innovations relative to the information set of investors, we can analyze the news content of major economic events as it is perceived by investors in real time. We explore how investors update beliefs around two closely watched economic events: news coming out from the Fed and the non-farm payroll announcements.

\subsection{Channels of the Fed's policy transmission}

There is growing evidence that the Fed impacts asset prices in a significant way. However, the channels through which this happens are less well understood. The conventional view is that news telegraphed by the Fed reveals either the current stance or the future path of monetary policy via exogenous shocks to short-term interest rates - what we refer to as the (conventional) monetary news channel. However, there is increasing evidence that the transmission also works through two other channels: the information channel, whereby the Fed reveals news about the state of the economy, and the risk-premium channel, whereby it influences the amount or the price of risk perceived by investors. The relative importance of the different channels is still debated (e.g., Bauer and Swanson, 2020, Hanson and Stein, 2015, Nakamura and Steinsson, 2018).

Those transmission channels map onto monetary $\left(\omega^{m}\right)$, growth $\left(\omega^{g}\right)$, and risk-premium news $\left(\omega^{p+}, \omega^{p-}\right)$, and thus we can assess their relative importance within a unified framework. We first study which shocks drive average asset returns on FOMC announcement days and over the full FOMC cycle. We then analyze the type of news that is captured by the standard measures of monetary policy surprises in the literature.

\subsection{News on FOMC days}

Lucca and Moench (2015) document that stocks earn high average excess returns over T-bills in the 24 hours before the scheduled FOMC announcements, but Treasury yields barely change on average over the same window. Both the strong response of stocks on FOMC days and the lack thereof in bonds have been considered a puzzle. Our framework allows us to understand not only 
the type of news that comes out on FOMC days but also why the results for stocks and bonds are so different. ${ }^{20}$

We regress log stock returns and yield changes as well as their historical decompositions (10) on the FOMC day dummy that equals one on scheduled FOMC announcement days and zero otherwise:

$$
z_{t}^{j} \text { or } z_{t}^{j}\left(\omega^{i}\right)=\gamma_{0}+\gamma_{1} 1_{t, \mathrm{FOMC}}+\varepsilon_{t} .
$$

We work with daily close-to-close returns rather than pre-FOMC returns: daily returns capture most of the effect documented by Lucca and Moench (2015). For consistency with much of the recent literature, we first focus on the post-1994 sample, when the Fed started making public announcements of its decisions. Before 1994, there remains uncertainty about the timing of when the Fed decision reached financial markets (Thornton, 2005). Figure 2 reports the estimated $\gamma_{1}$ coefficients along with robust $95 \%$ confidence intervals. Multiplying the coefficients for yield changes by the negative of duration (two and ten years, respectively), one obtains the coefficients for bond returns (as $r_{t}^{b,(n)}=-n \Delta y_{t}^{(n)}$ ), whose magnitude can be compared with that for stock returns. We focus on the estimates for the two- and ten-year yields to highlight the differences between short and long maturities. Results for the five-year yield are consistent with those maturities, and omitted for brevity.

Results. The first estimate in each panel of Figure 2 replicates the basic empirical fact. Stock returns are significantly higher on FOMC days, on average by 27.5 bps $(t=3.32)$, than on other days. By contrast, yields are not materially changed: Two- and ten-year yields on average decline by about a half basis point (statistically insignificant).

Subsequent estimates in each panel decompose the overall effect into contributions of individual shocks. The effect of growth news for both stock returns and yield changes is close to zero; thus, on average, FOMC days are not accompanied by systematically positive or negative news about the economy. Three shocks contribute positively to stock returns, accumulating into a large overall effect. Monetary shocks $\omega^{m}$ and both risk-premium shocks, $\omega^{p+}$ and $\omega^{p-}$, significantly raise stock

\footnotetext{
${ }^{20}$ As a plausibility check for our identification results, in Appendix Table IA-10 we show that monetary shocks are significantly more volatile on scheduled FOMC announcement days compared to other days, consistent with there being more monetary news on those days on average. Thus, although we do not exploit information about the timing of the FOMC announcements, our identification correctly detects an increase in the amount of monetary news on days when such news is likely to be prevalent. The discussion in the current section instead focuses on the average effect of news (i.e., their direction) on asset prices rather than the volatility of news.
} 
returns (all significant at the $10 \%$ level or better). In contrast to stocks, the contributions of shocks to yields are mixed. Monetary news $\omega^{m}$ and the common premium shocks $\omega^{p-}$ reduce the ten-year yield, while the hedging premium shocks $\omega^{p+}$ increase it. The final estimate in each panel of Figure 2 reports the joint contribution of the two risk-premium shocks. For yields, their combined impact is not statistically different from zero. For stocks, however, the risk-premium shocks account for more than two-thirds $(68 \%(=18.7 \mathrm{bps} / 27.5 \mathrm{bps}))$ of the overall average increase in returns.

Interpretation. These results suggest that stock price movements on FOMC days since the mid1990s primarily reflect downward shifts in the risk premium. The reduction in the hedging premium implies that the insurance provided by bonds becomes less valuable for investors. A combination of opposing effects of shocks on yields clarifies why previous studies have failed to find significant returns in bonds on FOMC days. There is an additional effect of more monetary easing news coming out on those days, as supported by the evidence that in the last couple of decades the Fed has eased more aggressively than the public expected (Bauer and Swanson, 2020, Cieslak, 2018). However, the overall economic magnitude of the risk premium channel is significantly larger than that of monetary easing shocks via the short rate.

To the extent that common premium shocks are associated with risk compensation for monetary news, capturing investors' uncertainty about the discount rates in the economy, it is plausible that the Fed can affect this source of risk premium. The hedging premium decline on FOMC days suggests that, with stable inflation expectations from mid-1990s, the Fed has also managed to reduce the uncertainty about the real side of the economy more effectively. If so, we should observe that the hedging premium effect is weaker in the pre-1994 sample, during which the growth-inflation tradeoff was more pronounced. Evidence for the pre-1994 period is consistent with this intuition.

Pre-/post-1994 comparison. The high average FOMC-day stock returns emerge particularly strongly from the mid-1990s. In the 1983-1993 period, stock returns are 19 bps $(t=1.82)$ higher on FOMC days relative to other days, or about 9 bps lower than in the post-1994 sample. An important question is thus what has changed around the mid-1990s. Our decomposition attributes effectively the entire pre-1994 average stock return to the common premium shocks; the effect of monetary news on stocks is roughly zero. Importantly, the impact of the hedging premium shocks also vanishes, indicating that the Fed's efficacy in reducing uncertainty about the real side of the economy was more limited in the earlier sample. This would be the case if the Fed's actions to prop 
up investors' confidence about the real economy simultaneously induced fears of recurrent persistent inflation, with its negative consequences for growth. Details of the pre-/post-1994 comparison are provided in Appendix Figure IA-8.

Robustness. We replicate the analysis in Figure 2 using spliced-sample estimates, combining shocks and historical decompositions estimated over pre- and post-1997 samples to account for the changing comovement between stocks and bonds. The split-sample estimates do not materially alter our conclusions about the dominant role of risk-premium shocks on FOMC days (Appendix Figure IA-9). Likewise, we obtain very similar results if we reestimate the model on the post1994 sample. We also consider the role of model uncertainty and study the distribution of the $\gamma_{1}$ coefficients in regression (11) using all retained solutions. The significant impact of risk premium shocks (especially the common premium $\omega^{p-}$ ) and monetary easing shocks is a robust finding across solutions (Appendix Figure IA-10).

[Figure 2 about here.]

\subsection{News over the FOMC cycle}

The FOMC day returns are part of a broader pattern in average stock returns between scheduled FOMC meetings. Analyzing the timing of various Fed events, Cieslak et al. (2019, CMVJ) argue based on a series of facts that information from the Fed disproportionately arrives in "even weeks" in FOMC cycle time, i.e., weeks 0, 2, 4, and 6 measured starting from the last scheduled FOMC meeting, where week 0 contains the FOMC announcement day. Our identification helps verify this interpretation without relying on assumptions about the timing of the Fed's actions or communication. If even weeks are indeed associated with information from the Fed, the impact of specific shocks in those weeks should be qualitatively similar to that on FOMC announcement days, documented in the preceding section. Week 0 already contains the FOMC day; therefore, we are particularly interested in what happens in the other even weeks.

Results. We revisit and extend CMVJ's evidence by analyzing the shock-specific drivers of the average even-week returns. Table 1 estimates the baseline CMVJ regressions of stock returns and yield changes on even-week dummy variables (separately for days falling in week 0 and days falling 
in any of the weeks 2, 4, and 6). Column (1) confirms the main result in CMVJ. Columns (2)-(6) decompose this result into specific shocks.

Several facts point to even weeks indeed being similar in terms of news content to the FOMC days. The direction with which a given shock affects stocks and yield in even weeks is consistent with its sign on the FOMC day in Figure 2. The high even-week returns on stocks arise primarily due to risk premium news. Finally, there is also evidence of more monetary easing news coming out in weeks 2,4 , and 6 on average.

The bulk of the high even weeks returns in stocks is due to the common premium shocks $\omega^{p-}$ that induce a reduction in the equity risk premium (Table 1 Panel A). Investigating individual day returns more closely, we find that common premium news is also significant on the day before the FOMC announcement, which drives large part of the pre-FOMC return in week 0 (not reported in any table). Similarly, more than $40 \%$ of the average daily returns in weeks 2,4 , and 6 stems from the common premium. Although hedging premium news $\omega^{p+}$ generates large positive return on FOMC days, its average daily contribution to even week returns is smaller than that of common premium, which indicates that the hedging premium effect at least partially dissipates over the FOMC cycle. ${ }^{21}$

Similar to FOMC days, the average responses of yields are much weaker and marginally significant only in week 0 for the ten-year maturity (column (1), Panels B and C of Table 1). However, shock-specific regressions reveal a negative and significant impact of the common premium shocks $\omega^{p-}$ across all even weeks, which implies a decrease in the Treasury premium. Monetary shocks in weeks 2, 4 and 6 further reinforce this effect by pushing yields down (with a marginal significance). This fact points to more news about monetary easing coming out in even weeks in FOMC cycle time, and parallels the finding of more monetary easing news also occurring on FOMC days.

Interpretation. CMVJ interpret the high even-week stock returns primarily as a consequence of the Fed's ability to reduce the risk premium by "a promise to act as needed." To argue that equity premium indeed declines in even weeks, they rely on premium estimates from Martin (2017) based on equity options. The results above support this interpretation, in addition allowing us to quantify

\footnotetext{
${ }^{21}$ Growth news contributes 4.2 bps to stock returns in week 0 . When we investigate the specific days, we find that the positive return due to growth news accrues after the announcement day (week 0 spans from the day before to three days after the announcement). This is consistent with the findings in Figure 2 that FOMC days themselves do not feature systematically positive or negative growth news.
} 
the role of the pure risk premium channel vis-à-vis the conventional monetary news channel. We find that the economic magnitude of the risk premium channel is significantly larger than the effect of monetary news via the risk-free rate, with risk-premium shocks driving about $65 \%$ of the average even-week stock returns. The fact that common premium shocks have a relatively larger impact on asset prices in even weeks compared to the hedging premium news suggests that the Fed can affect risk premium associated with discount-rate shocks more effectively than other sources of risk premium, in particular those arising from to uncertainty about growth.

[Table 1 about here.]

\subsection{A structural interpretation of monetary policy surprises}

The results so far demonstrate the average effect of different types of news on stocks and yields on days that contain significant information coming out from the Fed. A related approach is to study the responses of asset prices to monetary policy surprises. Surprises are usually measured as high-frequency changes in interest rates within a narrow window of the Fed announcement. The narrow event window identification allows one to focus on the news from the Fed, but in itself it also does not discern the particular type of news that the Fed conveys. Therefore, we use the term "monetary policy surprises" identified in the literature as distinct from monetary shocks $\omega^{m}$ in our identification.

The interpretation of monetary policy surprises is central to the current debate about policy transmission. Campbell et al. (2012) and Nakamura and Steinsson (2018) argue that an important part of the surprises stems from the Fed telegraphing information about economic growth, i.e., the information effect. Hanson and Stein (2015), instead, provide evidence consistent with changes in the risk premium induced by the Fed. These interpretations are non-exclusive. Thus, in order to assess the role of the information versus the risk-premium channels, over and above the conventional monetary news channel, we connect monetary policy surprises studied in the literature to our structural shock decomposition.

Measures of monetary policy surprises. We obtain monetary policy surprises following the approach of Gürkaynak et al. (2005a, GSS), updated by Swanson (2018). GSS/Swanson decompose changes in interest rates within a 30-minute window around the Fed announcements 
into an action and a communication surprise, which they refer to as the target and the path factor, respectively. ${ }^{22}$ The target factor measures a surprise change in the current policy target rate. The path factor is defined as a surprise change in forward guidance - news about the future short rate that is orthogonal to the target shock - and is identified from movements in longer-term interest rates. As such, the path factor is not a shock in a structural sense because longer-term rates reflect macroeconomic expectations and risk premia, and not just expectations of pure policy rate. Understanding what drives the path factor is thus at the heart of the current debate about the policy transmission.

Results. To link monetary policy surprises to different types of news, in Table 2, columns (1)-(4), we project the target and path surprises on the four $\omega$ shocks. We report results for the scheduled FOMC announcements post-1994 as well as all FOMC announcements (including unscheduled) over the 1991:7-2015:10 period considered by Swanson (2018). Regression coefficients are expressed in standard deviation units.

The monetary shock $\omega^{m}$ in our decomposition is the only variable that has explanatory power for the target factor. This result is intuitive as the target factor by construction should capture pure discount-rate news (shocks to the shortest maturity risk-free rate), as opposed to shocks to investors' expectations about the economy or to risk premia embedded in longer maturity yields. In contrast, the path factor is significantly related to all $\omega$ shocks except for the hedging premium, implying that path surprises aggregate different channels through which the Fed affects investors beliefs and asset prices. All significant loadings are positive. Thus, a negative path surprise can occur because of negative information about the economy revealed by the Fed $\left(\omega^{g}\right)$, news about expected monetary easing $\left(\omega^{m}\right)$, or news that reduces the common risk premium $\left(\omega^{p-}\right)$. In terms of magnitudes, the conventional monetary news is the largest component, followed by the common premium, and then by the growth news. ${ }^{23}$ The significance of the monetary and common premium

\footnotetext{
${ }^{22}$ We thank Eric Swanson who has graciously shared the data with us. Swanson (2018) updates the original GSS series through October 2015 and extends the GSS methodology to include large scale asset purchases (LSAP) surprises. The identification exploits changes in the short-term rates from the Fed fund and Eurodollar futures as well as some longer-term interest rates.

${ }^{23}$ These results help understand the finding of Gürkaynak et al. (2005a) that path surprises have a weak effect on stocks but a large effect on Treasury yields. We confirm this finding using scheduled meetings over the 1991-2007 sample, excluding the zero-lower bound period. Suppose we observe a negative path surprise. All structural shocks that the path factor embeds (growth, monetary, and common premium shocks) move yields in the same direction (downward), leading to an unambiguous impact of path surprises on yields. For stocks, however, the positive effect of monetary and premium news is partially offset by the negative effect of growth news, thus dampening the overall stock market response to path surprises.
} 
components indicates that the Fed announcement materially affects not only investors' beliefs about the path of monetary policy but also, via the risk premium channel, the uncertainty associated with that path. We also find evidence that the growth news effect strengthens in the period from 1994 up to the financial crisis (not reported separately in the table), consistent with the presence of an economically meaningful information effect in that sample.

Finally, given that post-2008 many Fed announcements involve unconventional policies, in column (5), we separately report results for the LSAP surprises constructed by Swanson (2018). Swanson identifies LSAP surprises by assuming that the LSAP factor is orthogonal to the target and path factors and as close to zero as possible during the pre-zero-lower-bound period. The sample starts in 2009 when the Fed first launched quantitative easing. Following Swanson (2018), we normalize the LSAP shock so that its positive value implies an increase in interest rates. The estimates indicate a sizeable risk-premium effect, with the common premium $\omega^{p-}$ having a large and positive coefficient, which implies a decline in the risk premium on both stocks and bonds associated with a negative LSAP shock. The significance of $\omega^{p-}$ shock is robust to omitting the most powerful announcement on March 18, 2009 (although the coefficient drops by a third). The significance of the hedging premium $\omega^{p+}$ is instead entirely driven by this single event. These results support the view that LSAP programs have worked primarily through reducing the premium on stocks and long-term bonds via the discount-rate risk channel rather than by signalling the future policy stance through the level of the short rate.

Overall, the analysis of monetary policy surprises complements the evidence in the preceding sections based on the average asset pricing effects on days with information from the Fed. The results highlight the multifaceted nature of information embedded in the Fed announcements, and in particular, their significant direct impact on beliefs about the policy path and the associated risk premium. The content of the announcements is also consistent with an information effect, although on average the Fed does not seem to reveal to the public systematically good or bad news about the economy.

[Table 2 about here.] 


\subsection{Interpreting the market reaction to non-farm payroll news: The monetary news channel}

Beyond news coming directly from the Fed, investors can also update their beliefs about the path of monetary policy and/or perceptions of risk in response to macroeconomic announcements. The interpretation of asset price responses to macroeconomic announcements has thus been challenging. Boyd et al. (2005) show that while announcements of rising unemployment are bad news for stocks in contractions, they are actually good news for stocks in economic expansions. Law et al. (2018) document that sensitivity of stocks to macroeconomic announcements varies systematically over the business cycle, and is particularly high when the economy is below potential. To disentangle the drivers of these results, we study how investors update beliefs over the business cycle in reaction to incoming non-farm payroll (NFP) data. We focus on the NFP announcements, as it is the most closely watched piece of macroeconomic news in the US (Andersen et al., 2007).

Empirical specification. We construct NFP surprises (actual minus expected) over the 1985:22017 period, using market participants' expectations of NFP before the announcement, with a positive surprise meaning good news. ${ }^{24}$ Following Law et al. (2018), we describe the state of the economy by the size of the unemployment rate gap, Gap $=-$ (Current unemployment rate Natural rate of unemployment). ${ }^{25}$ High values of the Gap variable imply that the economy is above potential (e.g., Gali et al., 2011). We distinguish three states of the economy (bad/neutral/good times) by splitting the values of the Gap into terciles of sample realizations. We then regress the announcement-day asset price changes onto six dummy variables reflecting the full set of interactions between NFP announcement dummies $(\mathrm{B}=\mathrm{bad} / \mathrm{G}=\operatorname{good}$ NFP news) and unemployment gap dummies $(\mathrm{B}=\mathrm{bad} / \mathrm{N}=$ neutral $/ \mathrm{G}=\operatorname{good}$ times $)$ :

$$
z_{t}^{j} \text { or } z_{t}^{j}\left(\omega_{t}^{i}\right)=\sum_{k} \beta_{k} 1_{t, k}+\varepsilon_{t}, \quad k=\{\mathrm{BG}, \mathrm{BN}, \mathrm{BB}, \mathrm{GG}, \mathrm{GN}, \mathrm{GB}\}
$$

The first letter in subscript $k$ indicates the type of NFP news; the second letter describes the overall state of the economy, e.g., $1_{\mathrm{BG}}$ is a dummy variable for days with bad NFP news coming out in good times. The slope coefficients $\beta_{k}$ in (12) measure the average stock return (yield change) conditional on bin $k$. Figure 3 presents $\beta_{k}$ estimates for stock returns; for brevity, we relegate the results for yield changes to Appendix Figure IA-11.

\footnotetext{
${ }^{24}$ The start of the sample is dictated by the availability of NFP forecasts. Before 1997, we use forecasts from Money Market Services and from 1997 onward from Bloomberg.

${ }^{25}$ Current unemployment is the real-time civilian unemployment rate obtained from the Federal Reserve Bank of Philadelphia. The natural rate of unemployment (NROU) is from Federal Reserve Bank of St. Louis FRED database.
} 
Results. The upper panels of Figure 3 (BG, BN, BB) demonstrate the ambiguous response of stocks to bad NFP news. While bad NFP news leads to negative stock returns in bad and neutral times (BN and $\mathrm{BB}$ ), bad NFP news in good times (BG) induces positive stock returns (30 bps on average), as documented by Boyd et al. (2005). Our decomposition reveals that, although the impact of growth news is negative, the positive stock market response in the BG panel can be entirely explained by investors updating beliefs about monetary policy toward an easier stance. This result is intuitive: In good times, communication by the Fed makes tightenings well anticipated. However, when bad NFP news arrives, investors perceive it as a signal that the tightening cycle would end (see also Appendix Figure IA-11, panel BG). Moving from the left to the right panel in the first row of Figure 3, the effect of monetary news weakens in neutral and bad times, making the negative effect of bad NFP news on stocks more direct (panels BN and BB): Stocks earn negative returns as investors revise downward their beliefs about growth.

The bottom panels of Figure 3 (GG, GN, GB) illustrate the effect of good NPF news. The negative effect of monetary news on stocks is visible when good NFP news arrives in good and neutral times (panels GG and GN). These are times when the prospect of the Fed's tightening dampens the positive NFP news. The offsetting effect of monetary news tapers off when the economy weakens, such that good NFP news in bad times (panel GB) have on average a positive impact on stocks.

Finally, the combined impact of the risk-premium news on stocks is insignificant across the six scenarios. Hence, one might conclude that risk premia do not move on NFP news. ${ }^{26}$ The common and hedging premium shocks can, however, have a distinct and individually large effect. In particular, good NFP news in bad times (GB) reduces the hedging premium $\omega^{p+}$ and increases the common premium $\omega^{p-}$ in stocks. To the extent that the two risk-premium shocks reflect a time-varying compensation for exposures to growth and monetary news, respectively, this result has an intuitive interpretation: Good NFP news in bad times reduces uncertainty about economic growth (hence $\omega^{p+}$ shocks push stocks up) but it also increases the uncertainty about discount rates as it may signal that an easing cycle would end (hence $\omega^{p-}$ shocks reduce stock prices). The reaction of Treasury yields is consistent with this interpretation, with both risk-premium shocks increasing the 10-year yield on bad NFP news in good times (Appendix Figure IA-11, panel GB).

\footnotetext{
${ }^{26}$ For example, Boyd et al. (2005) find an insignificant response of the equity risk premium to bad news in contractions.
} 
[Figure 3 about here.]

\section{Assessing the relative importance of $\omega$ shocks for asset prices since the early 1980s}

The results so far focus on selected Fed and macroeconomic events. In this section, we analyze how much of overall variation in yields and stock returns over the last 35 years is driven by the different economic shocks and how persistent the effects of those shocks are over time.

\subsection{Asset price responses to shocks across horizons}

Given that our reduced-form VAR relies on daily data, one may worry about inferring long-run effects of shocks from it directly. To study persistence, we therefore use the local projections approach of Jordà (2005). It is known that estimating the mean reversion in asset prices with VARs is plagued with econometrics issues. Local projections are more robust to misspecification and allow us to compute impulse-responses without specifying the full VAR dynamics. We regress multihorizon yield changes and log stock returns on the vector of $\omega$ shocks:

$$
Y_{t+d}^{j}-Y_{t-1}^{j}=\alpha_{d}+\beta_{d}^{j \prime} \omega_{t}+\varepsilon_{t-1, t+d}
$$

Horizon $d$ is in business days. The coefficient $\beta_{d}^{j, i}$ measures the impact of a one-standard-deviation shock in $\omega_{t}^{i}$ on a $(d+1)$-day yield change or stock return. Tracing out $\beta_{d}^{j, i}$ as a function of $d$, we obtain the cumulative impulse-response functions. Importantly, our identification assumptions only restrict contemporaneous effects of shocks on impact $(d=0)$, leaving responses for $d>0$ unconstrained.

Figure 4 plots the impulse responses for horizons up to three years estimated over the 1983-2017 sample. We compute the error bands with the Newey-West covariance matrix with $d+1$ lags, taking $\omega_{t}$ shocks from the MT solution as given. Hence, the error bands do not reflect shocks' estimation uncertainty (which is negligible, see Appendix Figure IA-4) nor uncertainty stemming from the set identification which can be significant. We present the distributions of the impulse-responses across all retained solutions in Appendix Figure IA-12. Moving across rows of Figure 4, we see how a particular shock impacts different assets. The size of on-impact responses is reported in the bottom left corner of each graph. 
Growth shocks generate positive responses in stocks and yields that mean-revert slowly with horizon, suggesting that those shocks operate at the business cycle frequency. Monetary shocks reveal economically large effects for yields with shorter maturities. ${ }^{27}$ For other assets, the effects of monetary shocks are weaker and mean-revert within about a year, broadly in line with estimates in the monetary literature. In contrast, premium shocks have a relatively long-lived effect, ${ }^{28}$ with hedging premium $\omega^{p+}$ persistently affecting all assets and the common premium shocks $\omega^{p-}$ predominantly affecting long-term yields and stocks. The persistent influence of premium shocks on stocks is noteworthy in connection to our evidence on the FOMC cycle in Section 4. In particular, the impulse-responses suggest that the Fed-induced reductions in the risk premium have had a persistent effect on raising stock market valuations from the early 1980s, as recently argued by Bianchi et al. (2019).

[Figure 4 about here.]

\subsection{Variance ratios}

To describe the relative contributions of different shocks to the overall variance of asset prices over our sample, we calculate variance ratios

$$
V R_{d}^{j, i}=\frac{\operatorname{Var}\left(u_{t}^{j} \mid \omega_{t}^{i}\right)}{\operatorname{Var}\left(u_{t}^{j}\right)},
$$

where $u_{t}^{j}$ is the reduced-form (daily) innovation to asset $j, \operatorname{Var}\left(u_{t}^{j} \mid \omega_{t}^{i}\right)$ is the variance of innovation to asset $j$ induced by shock $\omega_{t}^{i}$, and $\operatorname{Var}\left(u_{t}^{j}\right)$ is the overall variance of innovation to asset $j$. Since $\omega$ shocks are orthogonal, we have $\sum_{i=1}^{4} V R_{d}^{j, i}=1$. We construct the variance ratios for the full sample (1983-2017) and two subsamples, 1983-1997 and 1998-2017. We reestimate the model

\footnotetext{
${ }^{27} \mathrm{~A}$ one-standard-deviation monetary shock raises the two-year yield by 3.6 bps on impact which increases up to 8 bps at about two-year horizon. This magnitude is similar to the estimates based on Kuttner's surprises (Kuttner, 2001), which effectively capture surprise changes in the policy target. Using all (scheduled) meeting dates in Kuttner's sample (1989:06-2008:06), a one-standard-deviation surprise leads to a 3.7 bps (2.9 bps) increase in the two-year yield. Our estimates, however, are based on all dates, as opposed to the FOMC meeting dates for which Kuttner's surprises are available. The humped-shaped response is consistent with the evidence that investors' short-rate expectations have a sticky and extrapolative component, and thus adjust slowly to monetary news (Brooks et al., 2019, Cieslak, 2018).

${ }^{28}$ As such, our identified $\omega$ shocks deliver similar conclusions to Campbell and Ammer (1993) who find a small effect of risk-free rate shocks and a large effect of risk premium shocks on stocks, which they attribute to a high persistence of expected returns.
} 
for each subsample. ${ }^{29}$ Given that variance ratios can be sensitive to a particular solution in the identified set, in Figure 5 we report the average variance ratios across all retained solutions (bars) as well as ratios obtained with the MT solution (crosses) to show that they deliver qualitatively similar conclusions. Average variance ratios preserve the convenient property of summing to unity.

Focusing on the full sample in Figure 5 Panel A, nearly $80 \%$ of variation in the two-year yield comes from monetary and growth news, with monetary news contributing a slightly larger share. By contrast, around $80 \%$ of variation in the ten-year yield is explained by the risk-premium shocks. Risk-premium shocks also constitute nearly $60 \%$ of variation in stock returns. Monetary news explains less than $20 \%$ of the variation in stock returns and less than $10 \%$ in the ten-year yield changes. The rapidly declining effect of monetary news across yield maturities is consistent with the notion that those shocks mean revert and so should not have a major effect on long-duration assets. Compared to monetary news, the impact of growth news is relatively more persistent in the cross section of yields, with the five-year yield responding only slightly less than the two-year yield. ${ }^{30}$

Comparing the pre-/post-1998 subsamples in Panels B and C, we observe a decreased role of monetary news and increased role of growth news post-1998, especially visible for the two-year yield. Another pronounced change pertains to the contribution of the common premium shocks $\omega^{p-}$ to stocks, dropping to below $20 \%$ of stock return variance post-1998 from about $50 \%$ pre-1998, and accompanied by an increased contribution of the hedging premium shocks $\omega^{p+}$.

The results across subsamples cast light on the sources of the changing stock-yield comovement. Campbell et al. (2020) document that the risk premium is quantitatively important for explaining the change in stock-yield covariance from negative to positive in the late 1990s. Indeed, our findings suggest that risk-premium movements in recent decades increasingly reflect the timevarying compensation for growth news as opposed to discount-rate news. Given that the hedging (common) premium induces a positive (negative) comovement of stocks and yields, the shifts in

\footnotetext{
${ }^{29}$ The split in 1997 demarcates the time around which the comovement between stocks and yields changed sign from negative to positive, allowing us to study the drivers behind this change. For the subsample analysis, we do not require that the $A$ matrix remains constant. In Appendix $\mathrm{B}$, we show that the changing sign of the stock-yield covariance could arise from shifts in the volatility of structural shocks alone without a change in structural relations represented by matrix $A$.

${ }^{30}$ Our identification does not constrain the magnitudes of the incremental effects across yield maturities. For example, the contribution of monetary shocks could decrease slowly or quickly with maturity; likewise, different shocks could each have roughly the same or very different effects on a given asset. It is an empirical question, which of these patterns best characterizes the data.
} 
the relative importance of the two risk-premium shocks align with the change in the stock-yield comovement from negative to positive in the late 1990s. The variance ratios also help interpret a related finding that the comovement between stocks and yields, both at short and long maturities, is hard to explain by the "macro comovement" between expected inflation and growth news (Duffee, 2018b). According to Figure 5, the changing comovement at short maturities stems mainly from the decline in the contribution of monetary news relative to growth news, while the changing comovement at long maturities - from the decline in the contribution of the common premium news relative to the hedging premium news. The results for the short- and long-end of the yield curve are thus connected by the fact that they reflect a diminished effect of shocks associated with the discount rates.

[Figure 5 about here.]

\section{Validity of identified shocks}

This section provides additional evidence to assess the validity of our identification. We relate $\omega$ shocks to observable variables that are sensitive to economic shocks we aim to identify: economic forecasts from surveys and risk premium proxies proposed in the literature. We then interpret $\omega$ shocks through the lens of a stylized affine model with macro risk factors that embeds two distinct sources of time-varying risk premium in stocks and bonds.

\subsection{Link to macroeconomic expectations}

We begin by connecting $\omega$ shocks to macroeconomic expectations-forecasts of inflation and real GDP growth from the monthly BCEI survey. Using revisions in survey forecast, we show how forecasters update expectations at different future horizons in response to $\omega$ shocks. Survey revisions are not shocks in a structural sense as they reflect feedback effects between different structural factors driving macroeconomic expectations. However, similar to the approach in the macro literature that studies responses of macroeconomic aggregates to structural disturbances, we can assess whether shocks we identify are related with survey expectations in an economically meaningful way. 
Data and empirical specification. The BCEI survey expresses forecasts of real GDP growth (inflation) as percent changes in the real GDP (CPI) from the prior quarter, in annualized terms. In general, near-term forecasts for the current or next quarter are considerably more volatile than longer-horizon forecasts (see Appendix Figure IA-5). We define the forecast update at horizon $h$ as the revision in forecasts between two consecutive surveys (in month $t-1$ and $t$ ) for the same future calendar quarter, $\operatorname{Updt}_{t}\left(Z_{h}\right)=F_{t}\left(Z_{h}\right)-F_{t-1}\left(Z_{h}\right)$, where $F_{t}\left(Z_{h}\right)$ denotes forecast formed in month $t$, and $h$ denotes forecast horizon (in quarters) relative to the forecast month $t$ (making sure that forecasts at $t$ and $t-1$ refer to the same quarter). Given available data, we can construct updates from the current quarter $(h=0 q)$ up to three quarters ahead $(h=3 q)$. We then estimate regressions of the form

$$
\operatorname{Updt}_{t}\left(Z_{h}\right)=\gamma_{0}+\sum_{i} \gamma_{1}^{h, i} \omega_{t}^{i}+\operatorname{Updt}_{t-1}\left(Z_{h}\right)+\varepsilon_{t},
$$

where time $t$ is measured in months and the data is sampled monthly. The lag of the dependent variable accounts for sluggish expectations updating; it does not materially affect the loadings on $\omega$ shocks, but controls for any persistence in survey updates. To match the survey frequency, we sum daily $\omega$ shocks within a calendar month. ${ }^{31,32}$ Coefficients $\gamma_{1}^{h, i}$ represent forecast update of real GDP growth or inflation $h$ quarters ahead in response to a one-standard-deviation $\omega^{i}$ shock. Thus, one can interpret the pattern of coefficients across $h$ as a survey-based impulse response function (on a non-cumulative basis, given that forecasts are for percent changes from the previous quarter).

Real GDP forecast updates. One would expect survey forecasts of the real GDP growth to be highly sensitive to growth news. As a simple illustration of this fact, Figure 6 shows a close comovement between survey updates (at horizon of one quarter ahead $h=1 q$ ) and the identified growth shocks, with both series smoothed over 12 prior months for readability of the graph.

Figure 7 Panel A summarizes results from regressions in equation (15). Forecasters update their growth expectations positively with growth shocks $\left(\gamma_{1}^{h, g}\right.$ coefficients), as already indicated by the high correlation in Figure 6. Because growth forecasts are much more volatile at short horizons

\footnotetext{
${ }^{31}$ The BCEI survey publishes its results on the 10th of each month and the survey is conducted during several preceding days (exact dates are not reported). Thus, forecasters' information set mostly reflects news that came out during the previous calendar month. To make sure that $\omega$ shocks are not forward looking relative to survey updates, we merge survey published in a given month with shocks $\omega$ accumulated over the previous month.

${ }^{32}$ Our identification imposes that shocks are orthogonal at the daily frequency over the 1983-2017 sample. There is no guarantee that sums of shocks remain exactly orthogonal once converted to a lower frequency or in subsamples. However, we find that shock correlations are generally low at a monthly and quarterly frequency (see Appendix Table IA-11).
} 
(Appendix Figure IA-5 Panel A), we observe a strong response of near-term forecasts and a weaker but still positive and significant response at more distant horizons.

News of monetary easing leads to improved growth forecasts a couple of quarters out $\left(\gamma_{1}^{h, m}\right.$ coefficients). The negative relationship holds for all horizons except the current quarter, in line with the notion that monetary policy affects real activity with a lag. The positive coefficient for the current quarter $(h=0 q)$, instead, suggests that monetary easing coincides with the public downgrading their assessment of the current state of the economy. ${ }^{33}$ Finally, increases in both the hedging and the common premium are associated with downgrades to growth forecasts (coefficients $\left.\gamma_{1}^{h, p+}, \gamma_{1}^{h, p-}\right)$, consistent with the idea that adverse risk premium shocks can have a negative impact on the real economy (e.g., Christiano et al., 2014).

CPI inflation forecast updates. Figure 7 Panel B reports results from regression (15) using updates of inflation forecasts as the dependent variable. Overall, the statistical relationship between $\omega$ shocks with inflation forecasts is weaker than with growth forecasts: $\omega$ shocks explain up to $9 \%$ of variation in inflation forecast updates compared to nearly $30 \%$ of variation in growth forecast updates. An important observation is that forecasters revise inflation forecasts upward in response to growth shocks. This fact points to a procyclical inflation channel being an important force during our sample period, whereby positive growth news raises inflation going forward. In such environment, given that increases in the hedging premium feed into lower growth expectations $\left(\gamma^{h, p+}<0\right.$ coefficient in Panel A), they should also depress inflation expectations, as we find is indeed empirically the case $\left(\gamma^{h, p+}<0\right.$ coefficient in Panel B). We discuss a model that delivers these predictions in Appendix F.4.

The estimates for other shocks are, with few exceptions, economically small and insignificant. Of note is a weak but positive relationship between inflation forecast updates and monetary shocks. There are at least two possible interpretations of this result. The positive sign could indicate a nominal information effect, in which a monetary shock reveals to the public information about

\footnotetext{
${ }^{33}$ Note that the positive relationship $\gamma_{1}^{0 q, m}>0$ in Figure 7 Panel A is not isomorphic with the information effect, where the Fed directly reveals information about growth, and which we document in Section 4.4 using narrow window identification. Since in regression (15) we work with surveys at a monthly frequency, the positive relationship can arise if within a given month the Fed lowers interest rates (more than public expected as argued by Cieslak (2018)) in response to exogenous news and, at the same time, the public downgrades their growth expectations due to the same news. This interpretation along with the finding of $\gamma^{0 q, m}>0$ is consistent with evidence in Bauer and Swanson (2020), and in particular with "the Fed response to news" channel that they document.
} 
inflation (Pflueger and Rinaldi, 2020, Romer and Romer, 2000). ${ }^{34}$ Alternatively, as we discuss in Section 2.2.3, $\omega^{m}$ shocks could conflate true monetary shocks with exogenous shocks to expected inflation. While we are not able to clearly distinguish between these two possibilities, the relationship between monetary shocks and inflation forecast updates is statistically and economically weak. As such, exogenous shocks to expected inflation are unlikely to be a dominant confounder in our identification.

We support the above interpretation in Appendix E by linking $\omega$ shocks to the variation in breakeven inflation (BEI) rates (the difference between nominal and TIPS yields) over the post-2003 sample when reliable TIPS data becomes available (Appendix Table IA-4 contains the details). BEI rate changes are positively related to growth news, consistent with procyclical inflation and the results in Figure 7 Panel B. Importantly, however, we show that BEI rates primarily reflect fluctuations of the risk premium, with the hedging premium $\omega^{p+}$ being their key driver. An increase in the hedging premium lowers BEI rates, as would be the case when procyclical inflation makes nominal bonds even more valuable than real bonds in terms of hedging real growth risk (see Appendix F.4 for further discussion). We also document that the exposure to hedging premium shocks generates a strong positive comovement between BEI changes and stock returns observed in recent decades, as positive $\omega^{p+}$ shocks lower both stock returns and BEI rates.

[Figure 6 about here.]

[Figure 7 about here.]

\subsection{Bond and equity risk premium proxies}

Our identification assumes that positive common premium shocks $\omega^{p-}$ increase the risk premium on stocks and bonds, whereas positive hedging premium shocks $\omega^{p+}$ increase the premium on stocks but lower the premium on bonds. Since the time-variation in equity and bond risk premia is not directly observable, we test and confirm these sign restrictions using risk premium estimates proposed in the literature. For the bond risk premium, we use the Cochrane and Piazzesi (2005, CP)

\footnotetext{
${ }^{34}$ Similarly, Bauer and Swanson (2020) find a positive relationship between GSS target surprises and Blue Chip updates of inflation expectations. The statistical significance of this result is low and, according to their interpretation, it could reflect "the Fed response to news" channel rather than a genuine information effect.
} 
factor and the cycle factor from Cieslak and Povala $(2015)(\widehat{c f})$, both available monthly. For the equity risk premium, we use updated quarterly CAY estimates from Lettau and Ludvigson (2001), monthly estimates from Kelly and Pruitt (2013, KP), as well as daily forward equity premium from Martin (2017). We are interested in establishing how innovations to those proxies comove with $\omega$ shocks. To construct innovations, we regress a proxy on its own lags, with the number of lags selected with the BIC.

Before discussing the results, several points are worth highlighting. First, the above proxies are estimated based on varying assumptions and exploiting different data (possibly involving nonfinancial market information). This leads to large heterogeneity and low correlations in the implied risk premium variation even within an asset class. Second, the correlations between equity and bond premium innovations are generally close to zero (Appendix Table IA-12), pointing to the challenge of jointly explaining the variation in risk premia on stocks and bonds with a single state variable. Finally, none of the risk-premium proxies (or their innovations) are constructed assuming that they capture pure risk-premium shocks that are uncorrelated with shocks to expectations of growth or monetary policy path. Therefore, to assess the importance of pure risk-premium shocks, we report results using the full set of $\omega$ shocks as well as $\omega^{p+}$ and $\omega^{p-}$ alone. We aggregate $\omega$ shocks to monthly (quarterly) frequency by summing daily shocks within a calendar month (quarter).

Table 3 Panel A reports results for the bond risk premium. Pure risk premium shocks account for most of the explained variation in innovations to both the $\mathrm{CP}$ and $\widehat{c f}$ factors. The $\omega^{p+}$ and $\omega^{p-}$ shocks explain $81 \%$ of monthly innovations in $\widehat{c f}$ while all four shocks explain $92 \%$. The corresponding numbers for the CP factor are $49 \%$ and $51 \%$. The loadings on the two risk-premium components have the expected signs: positive for the common premium $\omega^{p-}$ and negative for the hedging premium $\omega^{p+}$. The common premium $\omega^{p-}$ is the most significant shock in economic terms over the post-1983 sample. ${ }^{35}$

Table 3 Panel B presents similar analysis for the equity premium. In column (1), we use daily estimates from Martin (2017) available for the 1996-2012 sample. Martin (2017) calculates the lower bound on the forward equity premia for horizons up to one year. We report the results for

\footnotetext{
${ }^{35}$ Both Cochrane and Piazzesi (2005) and Cieslak and Povala (2015) show that their bond premium factors are consistent with no-arbitrage models. The high correlation of innovations in those factors with $\omega$ shocks indicates that we are able to identify risk-premium shocks despite relying on weaker assumptions than those required by the no-arbitrage framework.
} 
the one-year premium in the main text and for other maturities in the Appendix Table IA-13. Martin's premium increases with both $\omega^{p+}$ and $\omega^{p-}$ shocks, consistent with the sign restrictions we postulate. In terms of economic significance, the coefficient on $\omega^{p+}$ is about $50 \%$ larger than on $\omega^{p-}$, which agrees with the increased role of the hedging premium shocks from the late 1990s documented in Section 5.2. Pure risk-premium shocks span $38 \%$ of daily changes in Martin's premium (all four shocks span 56\%). Turning to the KP and CAY variables, we also find that the coefficients on $\omega^{p-}$ and $\omega^{p+}$ are positive and statistically significant. All $\omega$ shocks jointly explain $8.1 \%$ of monthly innovations in KP and $21 \%$ of quarterly innovations in CAY, with $\omega^{p+}$ and $\omega^{p-}$ capturing $3.5 \%$ of variation in $\mathrm{KP}$ and $5.1 \%$ in CAY. The statistically weaker link between $\omega$ shocks and KP/CAY relative to Martin's estimates is not surprising. Martin's measure of the risk premium is tightly related to the implied variance of S\&P 500 index options, whose changes are in turn highly correlated with the $\mathrm{S} \& \mathrm{P}$ index returns underlying our identification. The KP/CAY proxies, instead, involve a broader information set (different equity portfolios in the case of KP or macroeconomic variables in the case of CAY).

The growth (monetary) shocks have a negative (positive) impact on innovations in the equity premium across the alternative measures. These signs agree with the view that equity risk premium is countercyclical (higher in bad economic times) and that monetary tightening increases the equity premium (Bekaert et al., 2013, Bernanke and Kuttner, 2005).

Overall, the results show that a non-negligible portion of variation in risk premium stems from pure risk-premium shocks and confirm the differentially signed impacts on the common and the hedging premium shocks on the risk compensation in bonds vis-à-vis equities. ${ }^{36}$

[Table 3 about here.]

\subsection{Model illustration and discussion}

This section presents a stylized affine asset pricing model which embeds shocks we seek to identify. We use this setting to rationalize our identification restrictions. We also introduce exogenous shocks to expected inflation (trend inflation shocks) to analyze their asset pricing implications and

\footnotetext{
${ }^{36}$ To tie our shocks to the time-variation in the levels of the stock and bond risk premia, we also estimate a lowfrequency VAR using identified $\omega$ shocks as external instruments. The results from the low-frequency VAR (available upon request) are consistent with the conclusions based on risk premium proxies we consider in this section.
} 
potentially confounding effects on shocks we identify empirically. Appendix F contains details and extensions to the basic setup presented below.

We assume that state variables evolve according to a $\operatorname{VAR}(1)$ process

$$
F_{t+1}=\mu_{F}+\Phi_{F} F_{t}+\Sigma_{F} \omega_{t+1}
$$

where $F_{t}$, with $\Phi_{F}$ stable, contains expected inflation $\tau_{t}$, expected real growth rate of the economy $g_{t}$, a monetary policy factor $m_{t}$, and two state variables driving time-varying market prices of risk $x_{t}^{+}, x_{t}^{-}, F_{t}=\left(\tau_{t}, g_{t}, m_{t}, x_{t}^{+}, x_{t}^{-}\right)^{\prime}$. Shocks $\omega_{t}=\left(\omega_{t}^{\tau}, \omega_{t}^{g}, \omega_{t}^{m}, \omega_{t}^{x^{+}}, \omega_{t}^{x-}\right)^{\prime}$ are independent and normally distributed $N(0,1)$, and $\Sigma_{F}$ is a diagonal matrix. The nominal one-period interest rate is determined by

$$
i_{t}=\delta_{0}+\delta_{\tau} \tau_{t}+\delta_{g} g_{t}+m_{t}=\delta_{0}+\delta_{1}^{\prime} F_{t}
$$

where $\delta_{1}=\left(\delta_{\tau}, \delta_{g}, \delta_{m}, 0,0\right)^{\prime}$ and we use normalization $\delta_{m}=1$. Equation (17) can be thought of as a forward looking Taylor rule, where $m_{t}$ captures (potentially persistent) deviations from the systematic component of the rule by the Fed. Realized inflation is $\pi_{t+1}=\tau_{t}+\sigma_{\pi} \varepsilon_{t+1}^{\pi}$ and realized nominal dividend growth is $\Delta d_{t+1}=g_{t}+\sigma_{d} \varepsilon_{t+1}^{d}+\pi_{t+1}$. We assume that $\varepsilon^{\pi}$, $\varepsilon^{d}$ shocks are not priced and are uncorrelated with $\omega$ shocks. The log nominal stochastic discount factor (SDF) evolves according to $\xi_{t+1}=-i_{t}-\frac{1}{2} \Lambda_{t}^{\prime} \Lambda_{t}-\Lambda_{t}^{\prime} \omega_{t+1}$, where $\Lambda_{t}=\Sigma_{F}^{-1}\left(\lambda_{0}+\Lambda_{1} F_{t}\right)$ determines the properties of the risk premia. With the above assumptions, the continuously compounded yield on the $n$-period nominal bond $\left(y_{t}^{(n)}\right)$ and the $\log$ price-dividend ratio $\left(p d_{t}\right)$ are affine functions of the state:

$$
\begin{gathered}
y_{t}^{(n)}=b_{n}+B_{n}^{\prime} F_{t} \\
p d_{t}=b_{s}+B_{s}^{\prime} F_{t},
\end{gathered}
$$

where $y_{t}^{(1)}=i_{t}$ and $p d_{t}=s_{t}-d_{t}$ with $s_{t}$ denoting the log stock market index and $d_{t}$ denoting log level of dividends. Coefficient vectors $B_{n}$ and $B_{s}$ have a well-known form provided in Appendix F. We use notation $B^{j}$ for a coefficient associated with $j$-th element of $F_{t}$.

Innovations to yields are $y_{t+1}^{(n)}-E_{t}\left(y_{t+1}^{(n)}\right)=B_{n}^{\prime} \Sigma_{F} \omega_{t+1}$ and innovations to the log $p d$ ratio are $p d_{t+1}-E_{t}\left(p d_{t+1}\right)=B_{s}^{\prime} \Sigma_{F} \omega_{t+1}$. Therefore, the signs of coefficients $B_{n}$ and $B_{s}$ determine the direction in which $\omega$ shocks move yield changes and stock returns. The effects are particularly transparent if the feedback matrix $\Phi_{F}$ in equation (16) is diagonal, which is the case we focus on 
below. The main intuition from the diagonal case extends to scenarios which allow for meaningful feedbacks between the state variables (see Appendix F). We also impose additional restrictions on the short-rate coefficients $\delta_{1}$, which are supported by empirical Taylor rule estimates (e.g., Clarida et al., 2000, Coibion and Gorodnichenko, 2012). Specifically, growth news impacts stocks and yields in the same direction $\left(B_{s}^{g}>0\right.$ and $\left.B_{n}^{g}>0\right)$, if the short rate moves less than one for one with expected growth $\left(0<\delta_{g}<1\right)$. With $\delta_{m}=1$, monetary news moves stocks and yields in opposite directions $\left(B_{s}^{m}<0\right.$ and $\left.B_{n}^{m}>0\right)$. As such, while bonds hedge growth shocks in stocks, both stocks and bonds are similarly exposed to pure discount-rate shocks via monetary news affecting the short rate.

In relation to the discussion in Section 2.2.3, we consider the impact of expected inflation news in this setting. A large literature suggests that post-1983, the Fed responded strongly to expected inflation, suggesting that $\delta_{\tau} \geq 1$. When $\delta_{\tau}=1$, a positive shock to expected inflation raises yields $\left(B_{n}^{\tau}>0\right)$, but has no effect on stocks $\left(B_{s}^{\tau}=0\right)$. Instead, when $\delta_{\tau}>1$, i.e., the so-called Taylor principle holds, a positive shock to expected inflation causes the stock market to fall and yields to increase $\left(B_{s}^{\tau}<0\right.$ and $\left.B_{n}^{\tau}>0\right)$. Thus, the impact of exogenous expected inflation news is akin to the pure discount-rate shock in that it moves stocks and yields in opposite directions (also satisfying the cross-maturity restrictions), just like monetary news does. This scenario would imply that monetary shocks we identify can subsume both the true monetary shocks as well as shocks to expected inflation. The evidence we provide using survey expectations of inflation in Section 6.1 suggests that such confounding effect is small over the period we analyze. ${ }^{37}$

Finally, the model illustrates the two sources of risk-premium variation which we posit in the empirical analysis. Suppose that investors earn time-varying risk premia for exposures to growth and monetary shocks $\omega^{g}$ and $\omega^{m}$, while risk premia for other shocks are constant. For example, investors can have distinct time-varying risk aversions over growth and monetary shocks, which we capture with reduced-form market price of risk factors $x_{t}^{+}, x_{t}^{-}$. Then, shocks to the $\log$ SDF are

$$
\xi_{t+1}-E_{t}\left(\xi_{t+1}\right)=-\lambda_{0}^{\prime} \Sigma_{F}^{-1} \omega_{t+1}-\frac{\lambda_{g x^{+}}}{\sigma_{g}} x_{t}^{+} \omega_{t+1}^{g}-\frac{\lambda_{m x^{-}}}{\sigma_{m}} x_{t}^{-} \omega_{t+1}^{m}
$$

\footnotetext{
${ }^{37}$ Empirically, we find that over the post-1983 period, expected inflation updates have an insignificant effect on the stock market, as shown in Appendix Table IA-1. In the model (16)-(19), expected inflation has no effect on stocks if the short rate loading on $\tau_{t}$ is unity $\left(\delta_{\tau}=1\right)$ and expected inflation does not feedback onto expected growth $g_{t}$ (i.e., $\left.\Phi_{F(2,1)}=0\right)$. Estimating a VAR using survey expectations for real GDP growth and CPI inflation over the post-1983 sample, we indeed find that the feedback of expected inflation on expected growth is not statistically different from zero. Appendix F.3 contains the details.
} 
implying that fluctuations in risk premia are driven by the two factors, $x_{t}^{+}, x_{t}^{-} \cdot 38$ Denoting the one-period log excess return on stocks and bonds respectively as $r x_{t+1}^{(n)}$ and $r x_{t+1}^{s}$, the risk premia $\operatorname{are}^{39}$

$$
\begin{aligned}
& E_{t}\left(r x_{t+1}^{(n)}\right)+\frac{1}{2} \operatorname{Var}_{t}\left(r x_{t+1}^{(n)}\right)=\text { const. } \underbrace{-(n-1) B_{n-1}^{g}}_{(-)} \lambda_{g x^{+}} x_{t}^{+} \underbrace{-(n-1) B_{n-1}^{m}}_{(-)} \lambda_{m x^{-}} x_{t}^{-}, \\
& E_{t}\left(r x_{t+1}^{s}\right)+\frac{1}{2} \operatorname{Var}_{t}\left(r x_{t+1}^{s}\right)=\text { const. }+\kappa_{1}(\underbrace{B_{s}^{g}}_{(+)} \lambda_{g x^{+}} x_{t}^{+}+\underbrace{B_{s}^{m}}_{(-)} \lambda_{m x^{-}} x_{t}^{-}),
\end{aligned}
$$

where $\kappa_{1}$ is a positive linearization constant slightly below unity. The risk premia inherit the respective asset's exposures to growth and monetary shocks via loadings $B^{g}$ and $B^{m}$. Because both stock and bond prices load on $\omega^{m}$ with the same sign, shocks to $x_{t}^{-}$move bond and equity premium in the same direction (generating a negative stock-yield comovement). Thus, the $x_{t}^{-}$ variable represents the time-variation in the common premium in stocks and bonds earned in compensation for pure discount-rate shocks to the risk-free rate. In contrast, because stocks and bonds load on $\omega^{g}$ with opposite signs, shocks to $x_{t}^{+}$move bond and stock premia in opposite directions (generating a positive stock-yield comovement). As such, the $x_{t}^{+}$variable captures the time-variation in the hedging premium on bonds vis-a-vis stocks earned in compensation for pure cash-flow shocks.

\section{Conclusions}

We propose a new approach to analyzing the sources of variation in asset prices. We exploit the fact that mainstream asset pricing models have a structural VAR representation. Economically interesting shocks can thus be uncovered from reduced-form VAR dynamics of asset prices combined with restrictions on how shocks affect those prices. We impose intuitive restrictions on how shocks to investors' expectations about the path of monetary policy (risk-free rate shocks), shocks to growth expectations as well as pure risk-premium shocks affect the joint dynamics of the stock market and the Treasury yield curve across maturities. Importantly, we allow for two sources of risk-premium news - the common and the hedging premium - capturing time-varying compensation for discount-

\footnotetext{
${ }^{38}$ In practice, we identify the signs of $\lambda_{g x^{+}}$and $\lambda_{m x^{-}}$jointly with $x_{t}^{+}$and $x_{t}^{-}$. Therefore, in our empirical approach, we assume $\lambda_{g x^{+}}>0$ and $\lambda_{m x^{-}}<0$ such that positive shocks to $x_{t}^{+}$and $x_{t}^{-}$both increase risk premia in stocks, and we denote $p_{t}^{+}=\lambda_{g x}+x_{t}^{+}$and $p_{t}^{-}=\lambda_{m x^{-}} x_{t}^{-}$.

${ }^{39}$ The nominal and real expected stock returns differ only by a constant, and so their responses to structural shocks are the same. For brevity of notation, we thus do not differentiate between real and nominal stock returns here.
} 
rate and cash-flow risk, respectively, and show that these shocks affect stocks and bonds in different ways.

We apply the identification to study the channels through which the Fed affects financial markets. The results highlight a direct effect of the Fed on asset prices via its ability to reduce both sources of risk premia, which strengthens from mid-1990s. More broadly, quantifying the importance of different shocks for asset prices since the early 1980s, we find that the relative importance of growth expectations and hedging premium news increased in the late 1990s, contributing to a switching sign of the comovement between stocks and bonds.

Our approach can be used to study the content of various events, with different models in the background. The identification restrictions we impose are deliberately weak and, as such, less subject to potential misspecification. One could tighten the identification in several ways, for example, by introducing narrative or event-based sign restrictions or constraints on the comovement between shocks and external variables (Antolín-Díaz and Rubio-Ramírez, 2018, Ludvigson et al., 2020), as well as by imposing further theory-motivated constraints on the shape of the yield curve, cross-section of stock portfolios, or additional assets. 


\section{References}

Ajello, A., Benzoni, L., Chyruk, O., 2020. Core and 'crust': Consumer prices and the term structure of interest rates. Review of Financial Studies 33, 3719-3765.

Andersen, T. G., Bollerslev, T., Diebold, F. X., Vega, C., 2007. Real-time price discovery in global stock, bond and foreign exchange markets. Journal of International Economics 73, 251-277.

Andreasen, M. M., Christensen, J. H., Riddell, S., 2018. The TIPS liquidity premium. Federal Reserve Bank of San Francisco.

Antolín-Díaz, J., Rubio-Ramírez, J. F., 2018. Narrative sign restrictions for SVARs. American Economic Review 108, 2802-29.

Arias, J. E., Caldara, D., Rubio-Ramírez, J. F., 2019. The systematic component of monetary policy in SVARs: An agnostic identification procedure. Journal of Monetary Economics 101, 1-13.

Baele, L., Bekaert, G., Inghelbrecht, K., 2010. The determinants of stock and bond return comovements. Review of Financial Studies 23, 2374-2428.

Balduzzi, P., Elton, E. J., Green, T. C., 2001. Economic news and bond prices: Evidence from the US Treasury market. Journal of Financial and Quantitative Analysis 36, 523-543.

Bansal, R., Shaliastovich, I., 2013. A long-run risk explanation of predictability puzzles in bond and currency markets. Review of Financial Studies 26, 1-33.

Bansal, R., Yaron, Y., 2004. Risks for the long run: A potential resolution of asset pricing puzzles. Journal of Finance 59, p. 1481 - 1509.

Bao, J., Pan, J., Wang, J., 2011. The illiquidity of corporate bonds. Journal of Finance 66, 911-946.

Bauer, M. D., Swanson, E. T., 2020. The Fed's response to economic news explains the "Fed information effect", working paper, UC Irvine.

Baumeister, C., Hamilton, J. D., 2015. Sign restrictions, structural vector autoregressions, and useful prior information. Econometrica 83, 1963-1999.

Bekaert, G., Cho, S., Moreno, A., 2010a. New Keynesian macroeconomics and the term structure. Journal of Money, Credit and Banking 42, 34-62.

Bekaert, G., Engstrom, E., Grenadier, S., 2010b. Stock returns with moody investors. Journal of Empirical Finance 17, 867-894.

Bekaert, G., Engstrom, E., Xing, Y., 2009. Risk, uncertainty and asset prices. Journal of Financial Economics 91, 59-82.

Bekaert, G., Hoerova, M., Lo Duca, M., 2013. Risk, uncertainty and monetary policy. Journal of Monetary Economics 60, 771-788.

Bernanke, B., Kuttner, K., 2005. What explains the stock market's reaction to Federal Reserve policy? Journal of Finance 60, 1221-1257.

Bianchi, F., Lettau, M., Ludvigson, S., 2019. Monetary policy and asset valuation, NBER working paper.

Boyd, J. H., Hu, J., Jagannathan, R., 2005. The stock market's reaction to unemployment news: Why bad news is usually good for stocks. Journal of Finance 60, 649-672.

Brooks, J., Katz, M., Lustig, H., 2019. Post-FOMC announcement drift in US bond markets, working paper, Stanford University.

Burkhardt, D., Hasseltoft, H., 2012. Understanding asset correlations, working paper, University of Zurich.

Campbell, J. R., Evans, C. L., Fisher, J. D., Justiniano, A., 2012. Macroeconomic effects of Federal Reserve forward guidance. Brookings Papers on Economic Activity 2012, 1-80.

Campbell, J. Y., 2018. Financial decisions and markets: A course in asset pricing. Princeton University Press.

Campbell, J. Y., Ammer, J., 1993. What moves the stock and bond markets? A variance decomposition for long-term asset returns. Journal of Finance 48, 3-37.

Campbell, J. Y., Pflueger, C., Viceira, L. M., 2020. Macroeconomic drivers of bond and equity risks. Journal of Political Economy 128, 3148-3185. 
Campbell, J. Y., Sunderam, A., Viceira, L. M., 2017. Inflation bets or deflation hedges? The changing risk of nominal bonds. Critical Finance Review 6.

Canova, F., Paustian, M., 2011. Business cycle measurement with some theory. Journal of Monetary Economics 58, 345-361.

Christiano, L. J., Motto, R., Rostagno, M., 2014. Risk shocks. American Economic Review 104, 27-65.

Cieslak, A., 2018. Short rate expectations and unexpected returns in Treasury bonds. Review of Financial Studies 31, 3265-3306.

Cieslak, A., Morse, A., Vissing-Jorgensen, A., 2019. Stock returns over the FOMC cycle. Journal of Finance 74, 2201-2248.

Cieslak, A., Povala, P., 2015. Expected returns in Treasury bonds. Review of Financial Studies 28, 2859-2901.

Cieslak, A., Povala, P., 2016. Information in the term structure of yield curve volatility. Journal of Finance 71, 1393-1436.

Cieslak, A., Schrimpf, A., 2019. Non-monetary news in central bank communication. Journal of International Economics 118, 293-315.

Clarida, R., Galí, J., Gertler, M., 2000. Monetary policy rules and macroeconomic stability: Evidence and some theory. Quarterly Journal of Economics 115, 147-180.

Cochrane, J. H., Piazzesi, M., 2005. Bond risk premia. American Economic Review 95, 138-160.

Cochrane, J. H., Piazzesi, M., 2008. Decomposing the yield curve, working paper, University of Chicago.

Coibion, O., Gorodnichenko, Y., 2012. Why are target interest rate changes so persistent? American Economic Journal: Macroeconomics 4, 126-162.

Connolly, R., Stivers, C., Sun, L., 2005. Stock market uncertainty and the stock-bond return relation. Journal of Financial and Quantitative Analysis 40, 161-194.

David, A., Veronesi, P., 2013. What ties return volatilities to price valuations and fundamentals? Journal of Political Economy 121, 682-746.

Dedola, L., Neri, S., 2007. What does a technology shock do? A VAR analysis with model-based sign restrictions. Journal of Monetary Economics 54, 512-549.

Duffee, G., 2018a. Expected inflation, real rates, and stock-bond comovement, working paper, Johns Hopkins University.

Duffee, G. R., 2018b. Expected inflation and other determinants of Treasury yields. Journal of Finance 73, 2139-2180.

Faust, J., 1998. The robustness of identified VAR conclusions about money. In: Carnegie-Rochester Conference Series on Public Policy, Elsevier, vol. 49, pp. 207-244.

Faust, J., Swanson, E. T., Wright, J. H., 2004. Identifying vars based on high frequency futures data. Journal of Monetary Economics 51, 1107-1131.

Fleckenstein, M., Longstaff, F. A., Lustig, H., 2014. The TIPS-Treasury bond puzzle. Journal of Finance 69, 2151-2197.

Fleming, M., Remolona, E., 2001. The term structure of announcement effects, working paper, Federal Reserve Bank of New York and BIS.

Fry, R., Pagan, A., 2005. Some issues in using VARs for macroeconometric research. Centre for Applied Macroeconomic Analyses, CAMA Working Paper 18.

Fry, R., Pagan, A., 2011. Sign restrictions in structural vector autoregressions: A critical review. Journal of Economic Literature 49, 938-60.

Gali, J., Smets, F., Wouters, R., 2011. Unemployment in an estimated New Keynesian model. NBER Macroeconomics Annual pp. 329-360.

Gallmeyer, M., Hollifield, B., Palomino, F., Zin, S., 2007. Bond pricing, habits and a simple policy rule, working paper, Carnegie Mellon University.

Granziera, E., Moon, H. R., Schorfheide, F., 2018. Inference for VARs identified with sign restrictions. Quantitative Economics 9, 1087-1121. 
Greenwood, R., Vayanos, D., 2014. Bond supply and excess bond returns. Review of Financial Studies 27, $663-713$.

Gürkaynak, R., Kisacikoglu, B., Wright, J., 2018. Missing events in event studies: Identifying the effects of partially-measured news surprises, working paper, Bilkent University and Johns Hopkins University.

Gürkaynak, R. S., Sack, B., Swanson, E., 2005a. Do actions speak louder than words? The response of asset prices to monetary policy actions and statements. International Journal of Central Banking 1, 55-93.

Gürkaynak, R. S., Sack, B., Swanson, E., 2005b. The sensitivity of long-term interest rates to economic news: Evidence and implications for macroeconomic models. American Economic Review 95, 425-436.

Gürkaynak, R. S., Sack, B., Wright, J. H., 2006. The U.S. Treasury yield curve: 1961 to the present, working paper, Federal Reserve Board.

Hanson, S. G., Stein, J. C., 2015. Monetary policy and long-term real rates. Journal of Financial Economics 115, 429-448.

Jarocinski, M., Karadi, P., 2020. Deconstructing monetary policy surprises - the role of information shocks. American Economic Journal: Macroeconomics 12, 1-43.

Jordà, Ò., 2005. Estimation and inference of impulse responses by local projections. American Economic Review 95, 161-182.

Kelly, B., Pruitt, S., 2013. Market expectations in the cross section of present values. Journal of Finance 68, $1721-1721$.

Kilian, L., Lütkepohl, H., 2017. Structural vector autoregressive analysis. Cambridge University Press.

Kim, D. H., Wright, J. H., 2005. An arbitrage-free three-factor term structure model and the recent behavior of long-term yields and distant-horizon forward rates, Finance and Economics Discussion Series 2005-33, Federal Reserve Board.

Koijen, R. S., Lustig, H., Van Nieuwerburgh, S., 2017. The cross-section and time series of stock and bond returns. Journal of Monetary Economics 88, 50-69.

Kozicki, S., Tinsley, P., 2001. Shifting endpoints in term structure of interest rates. Journal of Monetary Economics 47, 613-652.

Kuttner, K. N., 2001. Monetary policy surprises and interest rates: Evidence from the Fed funds futures market. Journal of Monetary Economics 47, 523-544.

Law, T. H., Song, D., Yaron, A., 2018. Fearing the Fed: How Wall Street reads Main Street, working paper, Johns Hopkins University.

Lettau, M., Ludvigson, S. C., 2001. Consumption, aggregate wealth, and expected stock returns. Journal of Finance 56, 815-849.

Lettau, M., Wachter, J., 2007. Why is long-horizon equity less risky? A duration-based explanation of the value premium. Journal of Finance 62, 55-92.

Lettau, M., Wachter, J. A., 2011. The term structures of equity and interest rates. Journal of Financial Economics 101, 90-113.

Lucca, D. O., Moench, E., 2015. The pre-FOMC announcement drift. Journal of Finance 70, 329-371.

Ludvigson, S. C., Ma, S., Ng, S., 2019. Uncertainty and business cycles: Exogenous impulse or endogenous response? American Economic Journal: Macroeconomics forthcoming.

Ludvigson, S. C., Ma, S., Ng, S., 2020. Shock restricted structural vector-autoregressions, NBER Working Paper No. 23225.

Martin, I., 2017. What is the expected return on the market? Quarterly Journal of Economics 132, 367-433.

Matheson, T., Stavrev, E., 2014. News and monetary shocks at a high frequency: A simple approach. Economics Letters 125, 282-286.

Nakamura, E., Steinsson, J., 2018. High frequency identification of monetary non-neutrality: The information effect. Quarterly Journal of Economics 133, 1283-1330.

Peersman, G., Straub, R., 2009. Technology shocks and robust sign restrictions in a euro area SVAR. International Economic Review 50, 727-750. 
Pflueger, C., Rinaldi, G., 2020. Why does the Fed move markets so much? A model of monetary policy and time-varying risk aversion, working paper, University of Chicago.

Pflueger, C., Viceira, L. M., 2016. Return predictability in the Treasury market: Real rates, inflation, and liquidity. In: Veronesi, P. (ed.), Handbook of Fixed-Income Securities, Wiley, chap. 10.

Piazzesi, M., Schneider, M., 2006. Equilibrium yield curves. NBER Macro Annual 21, 389 - 442.

Poole, W., Rasche, R. H., Thornton, D. L., 2002. Market anticipations of monetary policy actions. Federal Reserve Bank of St. Louis Review 84, 65-94.

Ramey, V. A., 2016. Macroeconomic shocks and their propagation. In: Handbook of Macroeconomics, Elsevier, vol. 2, pp. 71-162.

Rigobon, R., Sack, B., 2004. The impact of monetary policy on asset prices. Journal of Monetary Economics $51,1553-1575$.

Romer, C. D., Romer, D. H., 2000. Federal Reserve information and the behavior of interest rates. American Economic Review 90, 430-457.

Romer, C. D., Romer, D. H., 2004. A new measure of monetary policy shocks: Derivation and implications. American Economic Review 94, 1055-1084.

Rubio-Ramírez, J. F., Waggoner, D. F., Zha, T., 2010. Structural vector autoregressions: Theory of identification and algorithms for inference. Review of Economic Studies 77, 665-696.

Rudebusch, G. D., Wu, T., 2008. A macro-finance model of the term structure, monetary policy, and the economy. Economic Journal 118, 906-926.

Sargent, T. J., 1999. The Conquest of American Inflation. Princeton University Press.

Sims, C. A., 1980. Macroeconomics and reality. Econometrica 48, 1-48.

Song, D., 2017. Bond market exposures to macroeconomic and monetary policy risks. Review of Financial Studies 30, 2762-2817.

Stock, J., Watson, M., 2011. Modeling inflation after the crisis, FRB Kansas City Symposium, Jackson Hole, Wyoming, August 26-28.

Swanson, E. T., 2018. Measuring the effects of Federal Reserve forward guidance and asset purchases on financial markets, working paper, University of California, Irvine.

Swanson, E. T., Williams, J., 2014. Measuring the effect of the zero lower bound on medium- and longer-term interest rates. American Economic Review 104, 3154-3185.

Thornton, D. L., 2005. A new federal funds rate target series: September 27, 1982-December 31, 1993. Federal Reserve Bank of St. Louis Working Paper Series .

Thornton, D. L., 2006. When did the FOMC begin targeting the federal funds rate? What the verbatim transcripts tell us. Journal of Money, Credit and Banking 38, 2039-2071.

Uhlig, H., 2005. What are the effects of monetary policy on output? Results from an agnostic identification procedure. Journal of Monetary Economics 52, 381-419. 
A. growth news $\omega^{g}$

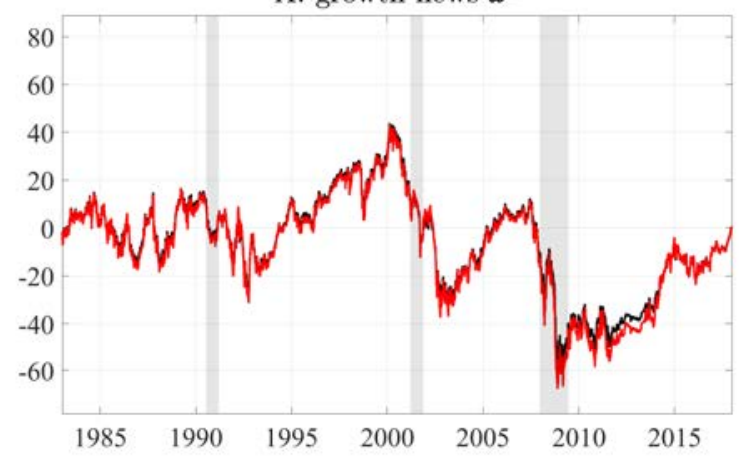

C. hedging premium news $\omega^{p+}$

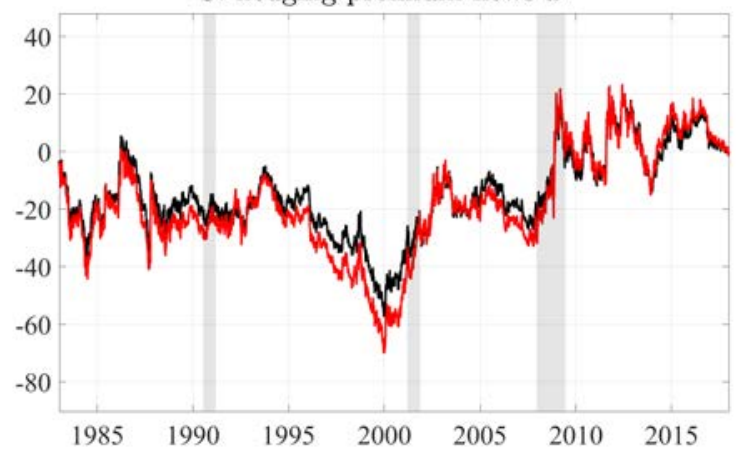

B. monetary news $\omega^{m}$

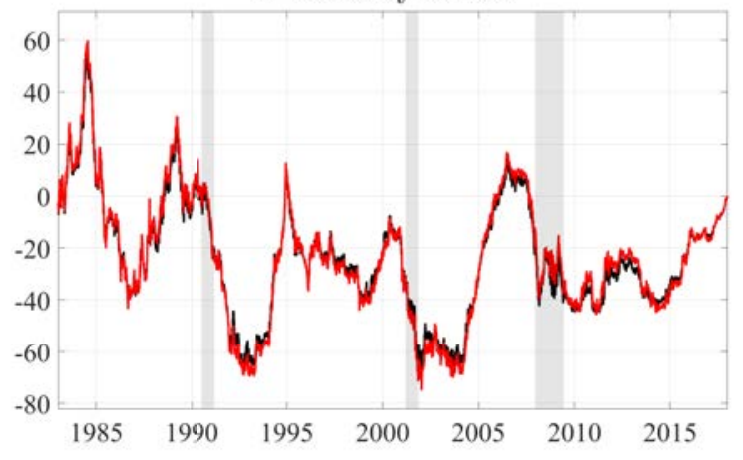

D. common premium news $\omega^{p-}$

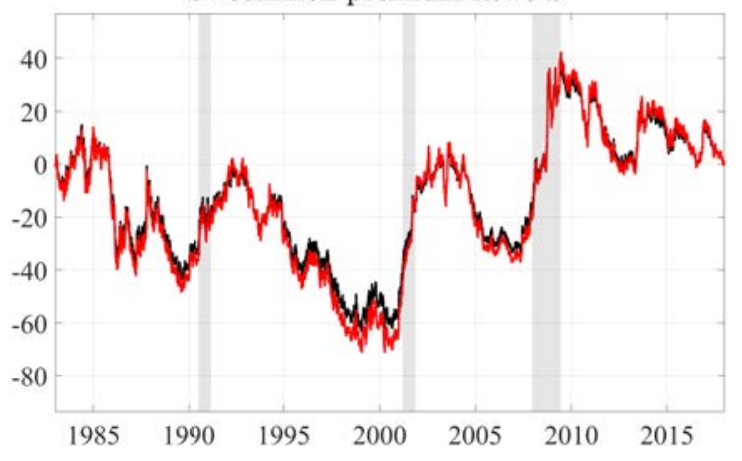

Figure 1. Paths of cumulative shocks. The figure presents paths of cumulative shocks for the MT solution and the median of cumulative shocks across all retained solutions. Cumulative paths are expanding-window sums of daily shocks. Daily shocks are normalized to have zero mean and unit standard deviation over the $1983-2017$ sample. Hence, the $y$-axis in the graph is expressed in standard deviation units. Paths of shocks start and end at zero by construction. Shaded areas indicate NBER-dated recessions. 
$\Delta s$

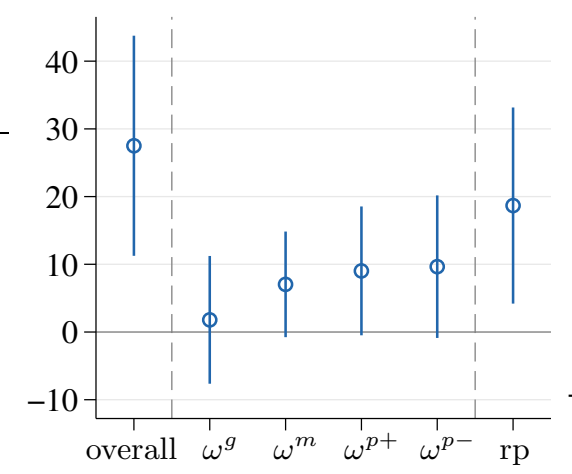

$\Delta y^{(2)}$

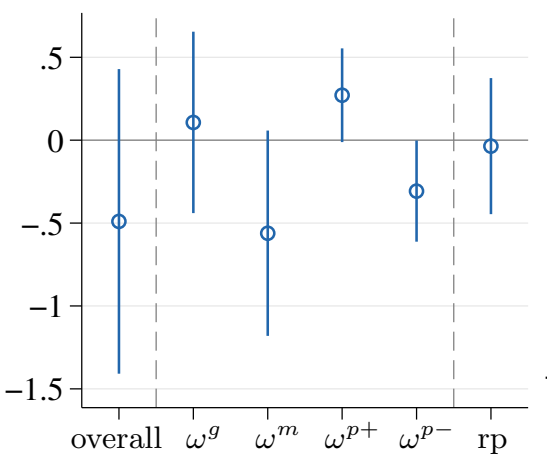

$\Delta y^{(10)}$

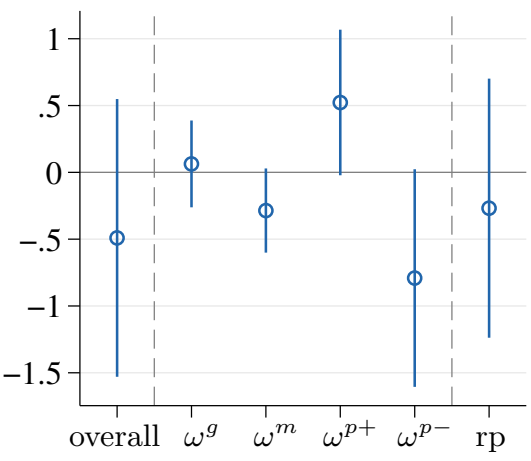

Figure 2. Stock returns and yield changes on scheduled FOMC announcement days. The figure reports the slope coefficients $\gamma_{1}$ from regression (11). All coefficients are in basis points. The first estimate in each panel represents the overall effect, i.e., the average change in stock returns (or yields) on FOMC days compared to all other days. For the next four estimates, the dependent variable is the historical decomposition (10) representing the part of the stock return (yield change) due to a particular shock $\omega^{i}, i=\{g, m, p+, p-\}$. Coefficients across $\omega$ 's sum up to the overall effect. The last estimate labelled "rp" separately reports the coefficient for the the overall risk-premium component (e.g., for stocks the dependent variable is $\Delta s\left(\omega^{p+}\right)+\Delta s\left(\omega^{p-}\right)$, and analogously for yields). Regressions are estimated over the 1994-2017 sample (6053 days), covering 192 scheduled FOMC meetings. The spikes indicate $95 \%$ confidence intervals based on standard errors robust to heteroscedasticity. 

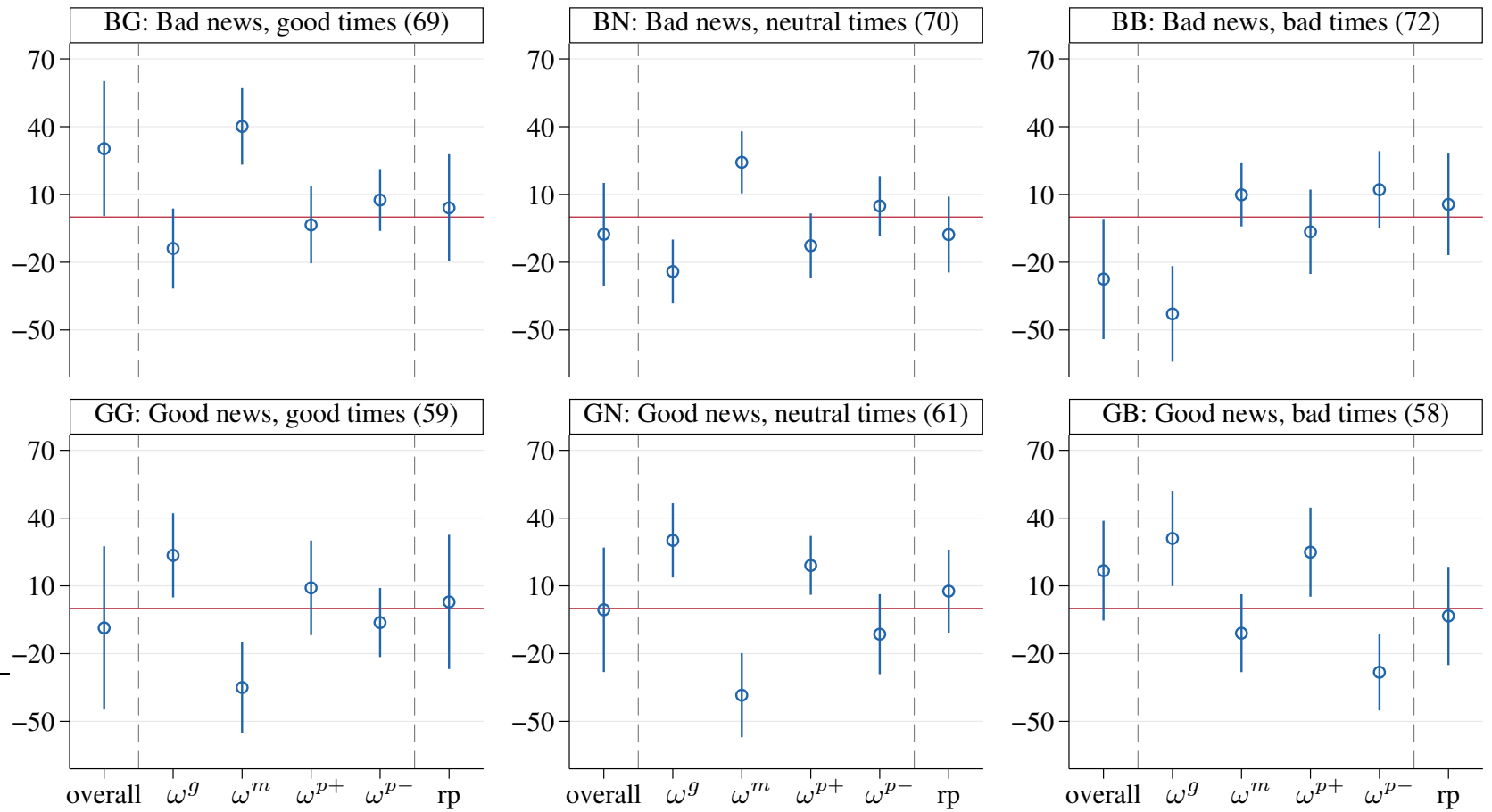

Figure 3. Stock returns on non-farm payroll announcement days. The figure reports average stock returns and their decompositions into contributions of structural shock on NFP announcement days, conditional on the type of news and the state of the economy. All numbers are in basis points. Good/Bad NFP news corresponds to a positive/negative NFP surprise (actual less expected NFP). The state of the economy (Good/Neutral/Bad times) is measured using terciles of the Gap variable, Gap $=-$ (Current unemployment - Natural rate of unemployment), with Gap in top tercile indicating good times. The estimates are obtained as $\beta_{k}$ coefficients from regression (12), $k=\{\mathrm{BG}, \mathrm{BN}, \mathrm{BB}, \mathrm{GG}, \mathrm{GN}, \mathrm{GB}\}$. Each subplot combines estimates of $\beta_{k}$ for a given $k$ from six regressions, using a different dependent variable each. The sample period is 1985:2-2017, with 389 NFP announcements for which we have both survey and actual numbers, excluding announcements that fall on a holiday. Before 1997, NFP surprises are from Money Market Services, and from 1997 onward from Bloomberg. In parentheses, we report the number of NFP announcements falling into bin $k$. The spikes indicate $95 \%$ confidence intervals based on robust standard errors. 

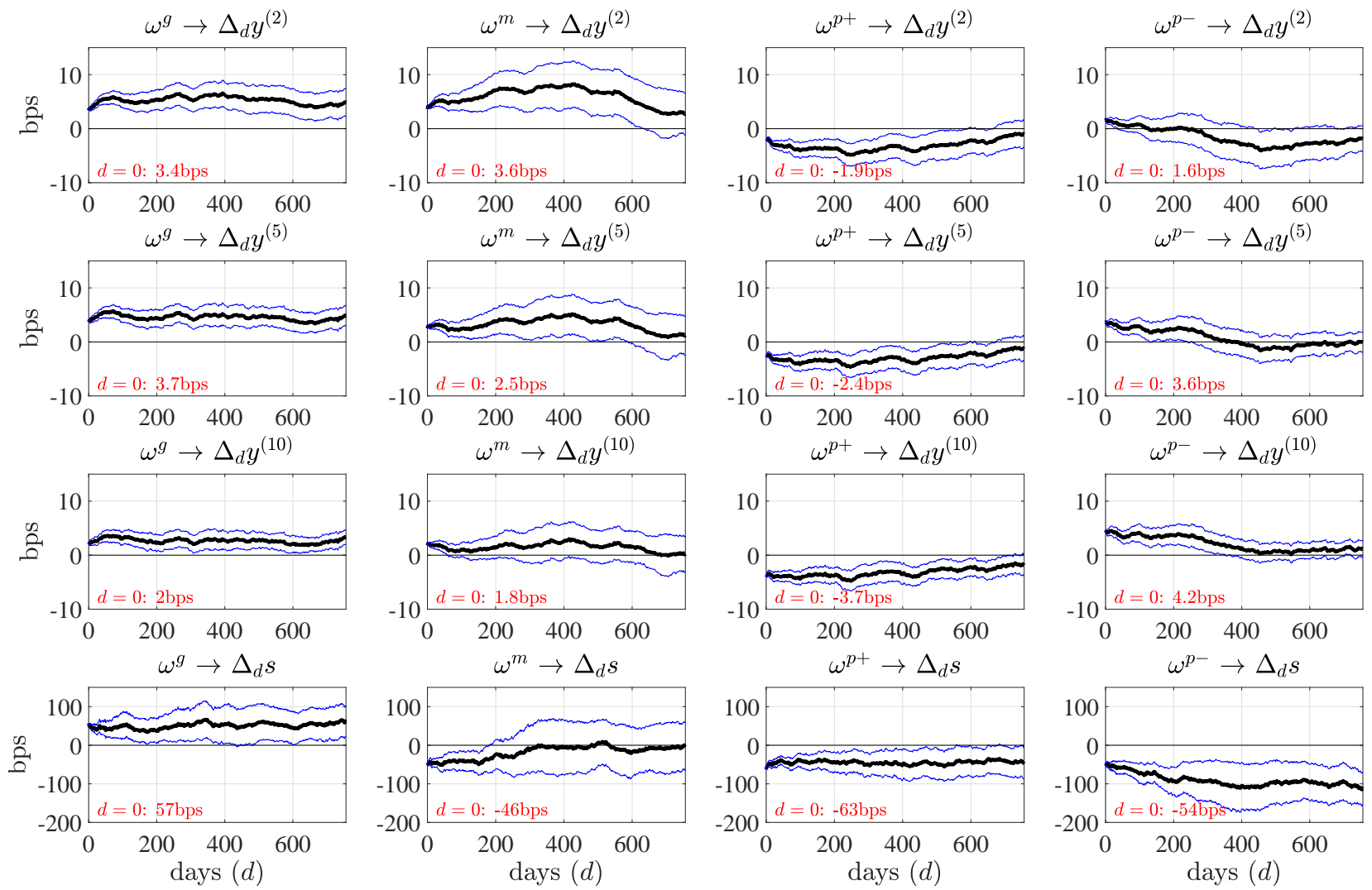

Figure 4. Impulse-response functions. The figure presents responses of yield changes and stock returns to $\omega$ shocks up to maximum horizon of three years (756 business days). Shocks correspond to the MT solution and are measured in standard deviation units. Yield changes and stock returns are in basis points. $\Delta_{d} x$ is a $d$-day change in variable $x$. The thick line traces out the coefficients $\beta_{d}^{j, i}$ from regression (13). A coefficient of 10 implies an asset response of $10 \mathrm{bps}$ to a one-standard-deviation shock. The thin lines mark $95 \%$ confidence intervals calculated with Newey-West adjustment using $d+1$ lags. The numbers in the bottom left corner of each graph report the size of the on-impact response (for $d=0$ ). The sample period is 1983-2017. 
A. $1983-2017$
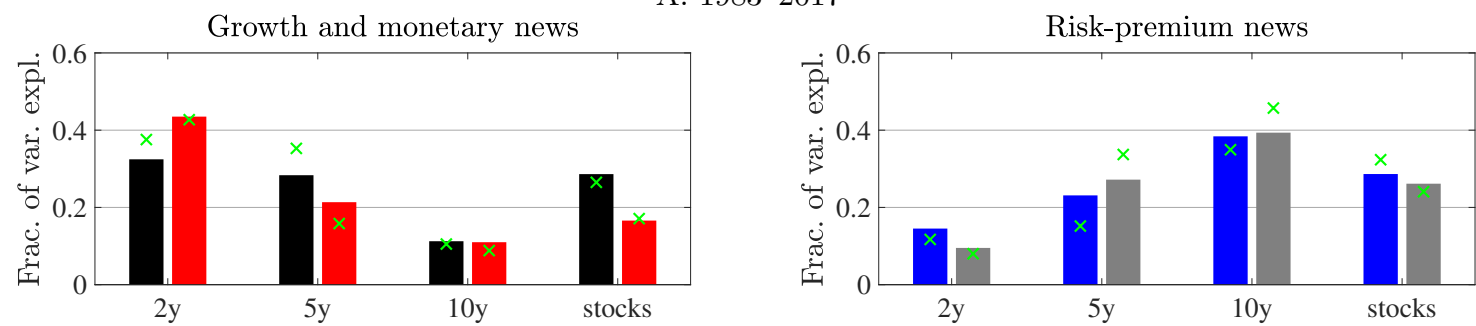

B. $1983-1997$
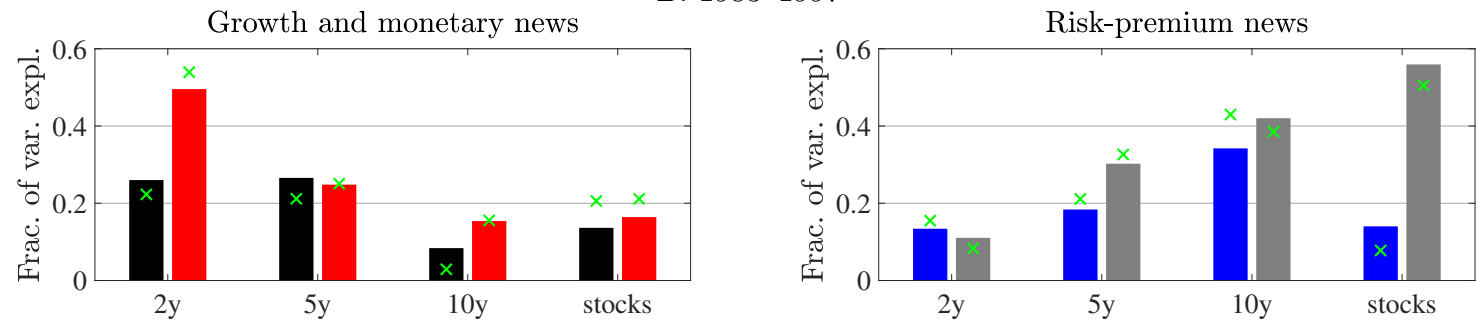

C. $1998-2017$
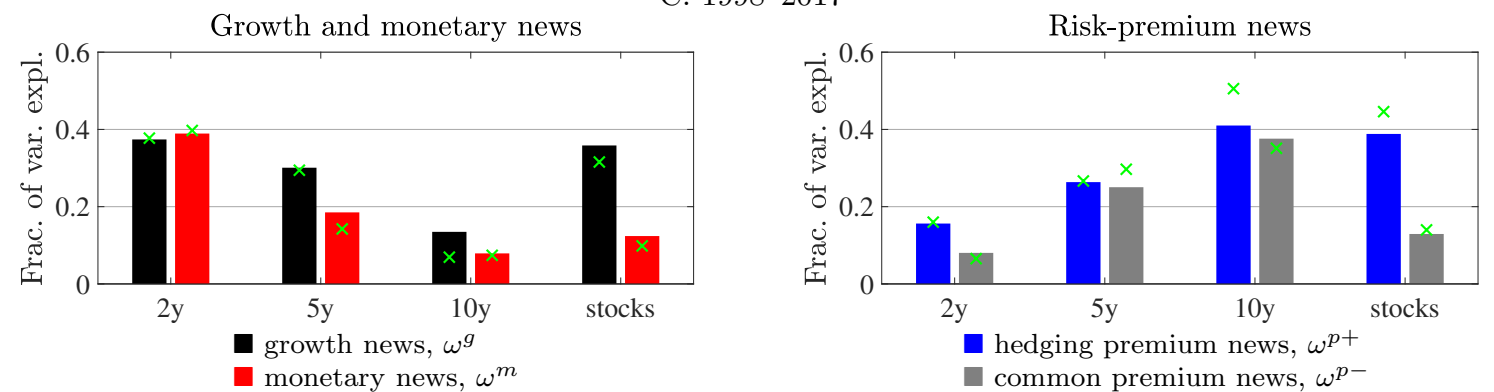

Figure 5. Variance ratios. The figure presents variance decompositions of innovations in daily yield changes with maturities of two, five, and ten years and stock returns into $\omega$ shocks. The bars show the fraction of variance explained by each shock on average across all retained model solutions. Crosses indicate the corresponding variance ratios implied by the MT solution. Variance ratios across shocks sum to unity by construction. Panel A reports full-sample estimates. Panels B and C are based on separate estimates for subsamples. 


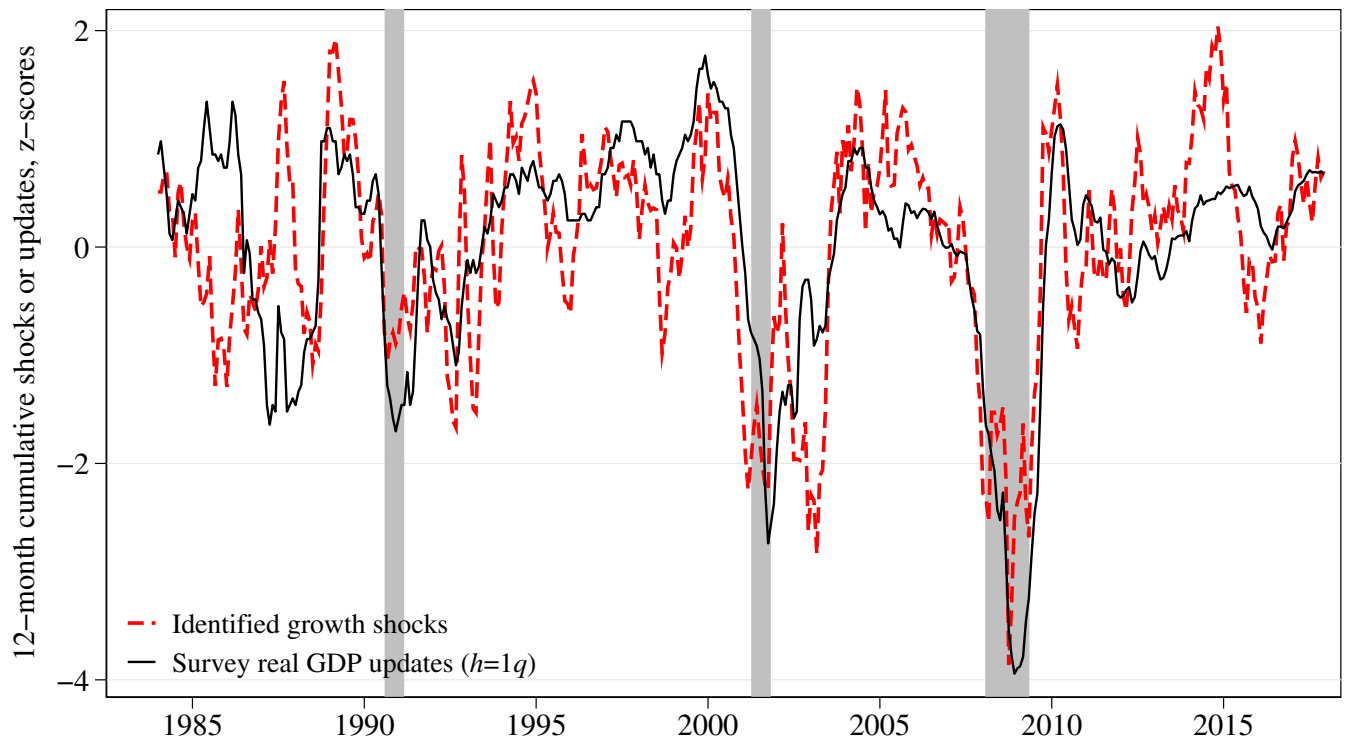

Figure 6. Comparison of identified growth shocks with survey forecast updates for the real GDP growth. The figure superimposes identified growth shocks with forecast updates of real GDP growth expectations from the BCEI survey. Both identified shocks and survey updates are cumulated over the past 12-month period. Survey updates are for one quarter ahead $(h=1 q)$. Both variables are standardized to have zero mean and unit standard deviation. 
A. Dependent variable: Expected real GDP growth updates
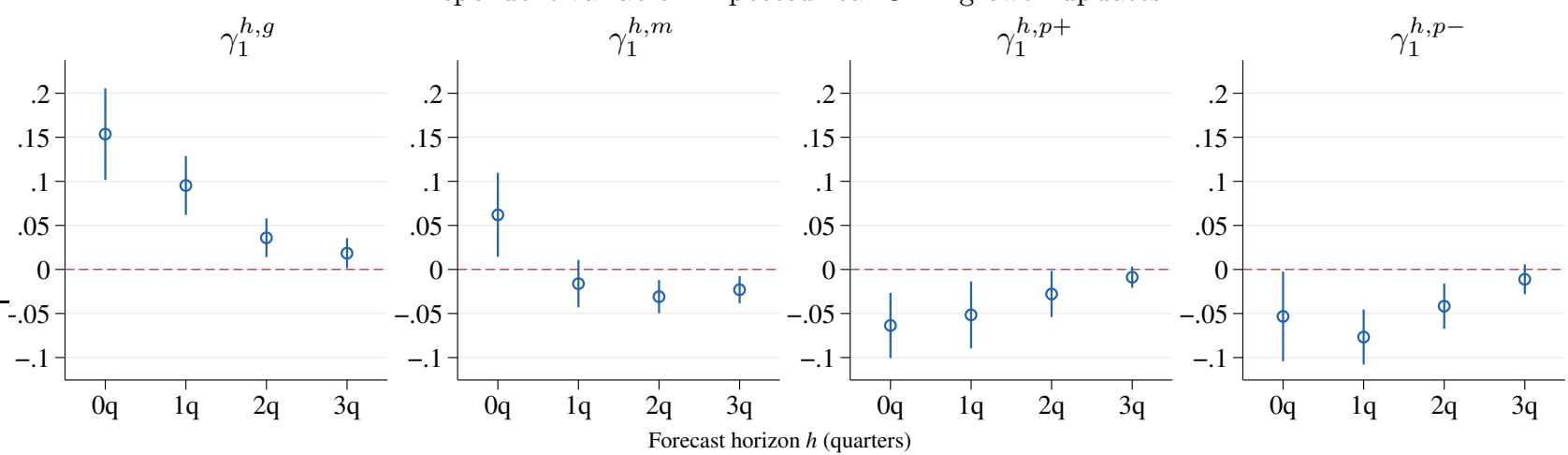

\begin{tabular}{lcccc} 
Forecast horizon, $h$ & $0 q$ & $1 q$ & $2 q$ & $3 q$ \\
\hline$R^{2}(\omega$ shocks $)$ & 0.25 & 0.29 & 0.16 & 0.07
\end{tabular}

B. Dependent variable: Expected CPI inflation updates
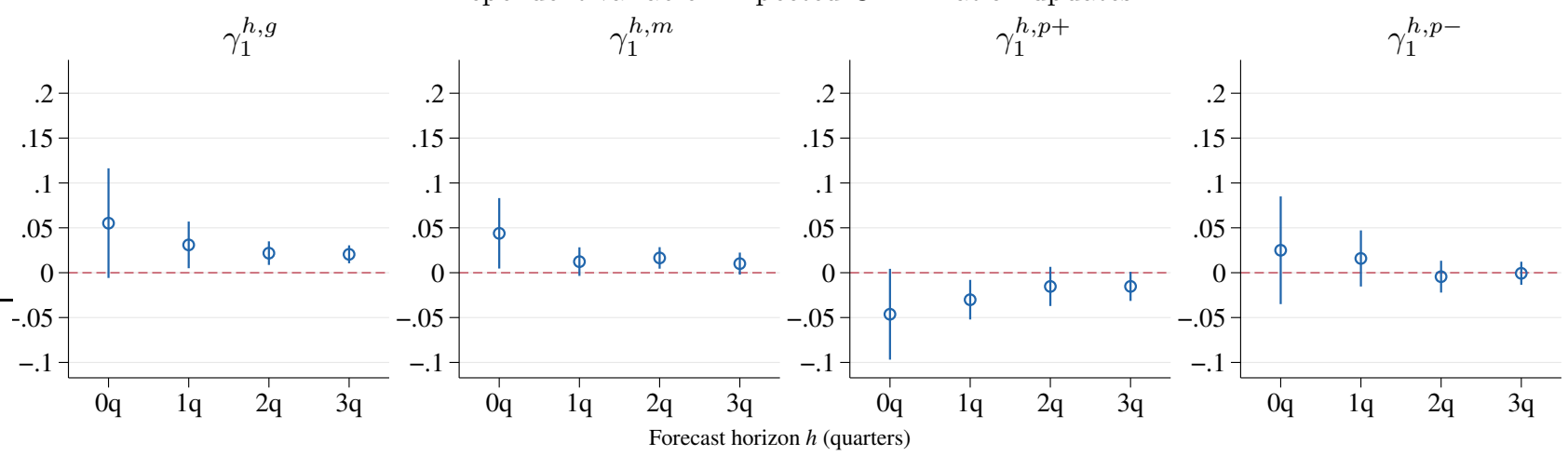

\begin{tabular}{lcccc} 
Forecast horizon, $h$ & $0 q$ & $1 q$ & $2 q$ & $3 q$ \\
\hline$R^{2}(\omega$ shocks $)$ & 0.05 & 0.08 & 0.06 & 0.09
\end{tabular}

Figure 7. Impact of $\omega$ shocks on survey expectations of real GDP growth and inflation. The figure presents estimates of slope coefficients $\gamma_{1}^{h, i}$ from regression (15). Each subplot reports coefficients for shock $\omega^{i}$ across different horizons $h$. The tables below the graphs display the fraction of forecast updates' variance explained by $\omega$ shocks alone (i.e., without the lagged dependent variable). Real GDP growth and CPI inflation forecasts are percent changes from the previous quarter and reported at annual rates; updates are defined as changes in those forecasts between consecutive surveys. The data is at a monthly frequency. $\omega$ shocks are aggregated to monthly frequency by summing daily shocks within a calendar month and standardized to have zero mean and unit standard deviation. The spikes indicate 95\% confidence intervals based on robust standard errors. The sample period is 1983-2017. 


\begin{tabular}{|c|c|c|c|c|c|c|}
\hline & $(1)$ & $(2)$ & $(3)$ & $(4)$ & $(5)$ & $(6)$ \\
\hline & Overall & \multicolumn{5}{|c|}{ Of which due to shock: } \\
\hline & $\Delta s$ or $\Delta y^{(n)}$ & $\omega^{g}$ & $\omega^{m}$ & $\omega^{p+}$ & $\omega^{p-}$ & $\omega^{p+}, \omega^{p-}$ \\
\hline \multicolumn{7}{|c|}{ A. Log stock returns $\Delta s$ (bps), $N=6050$} \\
\hline Week 0 dummy & $\begin{array}{c}13.4^{* * *} \\
(3.08)\end{array}$ & $\begin{array}{c}4.21^{* *} \\
(1.99)\end{array}$ & $\begin{array}{c}0.87 \\
(0.52)\end{array}$ & $\begin{array}{c}0.62 \\
(0.25)\end{array}$ & $\begin{array}{c}7.69 * * * \\
(3.77)\end{array}$ & $\begin{array}{c}8.31^{* * *} \\
(2.58)\end{array}$ \\
\hline Week $2,4,6$ dummy & $\begin{array}{c}10.2^{* * *} \\
(3.02)\end{array}$ & $\begin{array}{c}1.27 \\
(0.80)\end{array}$ & $\begin{array}{c}2.03 \\
(1.64)\end{array}$ & $\begin{array}{c}2.65 \\
(1.45)\end{array}$ & $\begin{array}{c}4.27^{* * *} \\
(3.03)\end{array}$ & $\begin{array}{c}6.92^{* * *} \\
(2.97)\end{array}$ \\
\hline \multicolumn{7}{|c|}{ B. Two-year yield changes $\Delta y^{(2)}(\mathrm{bps}), N=6050$} \\
\hline Week 0 dummy & $\begin{array}{l}-0.031 \\
(-0.15)\end{array}$ & $\begin{array}{c}0.26^{* *} \\
(2.07)\end{array}$ & $\begin{array}{l}-0.075 \\
(-0.56)\end{array}$ & $\begin{array}{l}0.020 \\
(0.27)\end{array}$ & $\begin{array}{c}-0.24^{* * *} \\
(-4.01)\end{array}$ & $\begin{array}{c}-0.22^{* *} \\
(-2.25)\end{array}$ \\
\hline Week 2, 4, 6 dummy & $\begin{array}{l}-0.13 \\
(-0.85)\end{array}$ & $\begin{array}{l}0.082 \\
(0.87)\end{array}$ & $\begin{array}{l}-0.16^{*} \\
(-1.66)\end{array}$ & $\begin{array}{l}0.082 \\
(1.50)\end{array}$ & $\begin{array}{c}-0.13^{* * *} \\
(-3.22)\end{array}$ & $\begin{array}{l}-0.049 \\
(-0.72)\end{array}$ \\
\hline \multicolumn{7}{|c|}{ C. Ten-year yield changes $\Delta y^{(10)}$ (bps), $N=6050$} \\
\hline Week 0 dummy & $\begin{array}{c}-0.46^{* *} \\
(-2.01)\end{array}$ & $\begin{array}{c}0.15^{* *} \\
(2.06)\end{array}$ & $\begin{array}{l}-0.039 \\
(-0.57)\end{array}$ & $\begin{array}{l}0.040 \\
(0.27)\end{array}$ & $\begin{array}{c}-0.62^{* * *} \\
(-3.91)\end{array}$ & $\begin{array}{c}-0.58^{* * *} \\
(-2.67)\end{array}$ \\
\hline Week 2, 4, 6 dummy & $\begin{array}{l}-0.22 \\
(-1.28)\end{array}$ & $\begin{array}{l}0.048 \\
(0.86)\end{array}$ & $\begin{array}{c}-0.084^{*} \\
(-1.67)\end{array}$ & $\begin{array}{c}0.16 \\
(1.50)\end{array}$ & $\begin{array}{c}-0.34^{* * *} \\
(-3.14)\end{array}$ & $\begin{array}{c}-0.18 \\
(-1.21)\end{array}$ \\
\hline
\end{tabular}

Table 1. FOMC cycle regressions. The table reports regressions of daily log stock returns and daily yield changes on the even-week dummies defined as in CMVJ (2019). Starting with day 0 being the FOMC announcement day, the weeks in FOMC cycle time are: week $-1=$ days -6 to -2 ; week $0=$ days -1 to 3 ; week $1=$ days 4 to 8 ; week $2=$ days 9 to 13 ; week $3=$ days 14 to 18 ; week $4=$ days 19 to 23 ; week $5=$ days 24 to 28 ; week $6=$ days 29 to 33. All coefficients are in basis points. Regressions are estimated with a constant, which is suppressed in the output for brevity. In column (1), the dependent variable is the overall stock return or yield change. In columns (2)-(5), the dependent variables are the historical decompositions (10) of stock returns and yields changes into contributions of structural shocks. Column (6) separately reports the coefficients for the total risk-premium component (e.g., for stock returns the dependent variable is $\left.\Delta s\left(\omega^{p+}\right)+\Delta s\left(\omega^{p-}\right)\right)$. Regressions are estimated over the 1994-2017 sample, covering 192 scheduled FOMC meetings. $t$-statistics robust to heteroscedasticity are reported in parentheses. $* / * * / * * *$ indicates significance at the $10 \% / 5 \% / 1 \%$ level. 


\begin{tabular}{|c|c|c|c|c|c|}
\hline & (1) & (2) & (3) & (4) & (5) \\
\hline & \multirow{2}{*}{\multicolumn{2}{|c|}{$\begin{array}{l}\text { all meetings } \\
\text { 1991:7-2015:10 }\end{array}$}} & \multirow{2}{*}{\multicolumn{2}{|c|}{$\begin{array}{c}\text { scheduled meetings } \\
1994-2015: 10\end{array}$}} & \\
\hline & & & & & $2009-2015: 10$ \\
\hline & Target & Path & Target & Path & LSAP \\
\hline \multirow[t]{2}{*}{$\omega^{g}$} & 0.052 & $0.170^{*}$ & 0.100 & $0.256^{* * *}$ & 0.108 \\
\hline & $(0.50)$ & $(1.86)$ & (1.01) & $(2.84)$ & $(0.88)$ \\
\hline \multirow[t]{2}{*}{$\omega^{m}$} & $0.563^{* * *}$ & $0.375^{* * *}$ & $0.396^{* * *}$ & $0.517 * * *$ & 0.027 \\
\hline & $(4.67)$ & $(3.83)$ & $(3.83)$ & $(6.53)$ & $(0.17)$ \\
\hline \multirow[t]{2}{*}{$\omega^{p+}$} & 0.011 & 0.010 & 0.008 & -0.064 & $-0.338^{* *}$ \\
\hline & $(0.16)$ & $(0.16)$ & $(0.11)$ & $(-0.97)$ & $(-2.22)$ \\
\hline \multirow[t]{2}{*}{$\omega^{p-}$} & -0.044 & $0.361^{* * *}$ & -0.011 & $0.352^{* * *}$ & $0.715^{* * *}$ \\
\hline & $(-0.63)$ & $(5.32)$ & $(-0.12)$ & $(4.53)$ & $(3.13)$ \\
\hline$R^{2}$ & 0.34 & 0.30 & 0.18 & 0.46 & 0.68 \\
\hline $\mathrm{N}$ & 213 & 213 & 175 & 175 & 55 \\
\hline
\end{tabular}

Table 2. Monetary policy surprises. The table reports regressions of GSS/Swanson surprises on $\omega$ shocks. GSS/Swanson surprises are from Swanson (2018) and are measured in a 30-minutes' window around FOMC announcements. Columns (1) and (2) use all meetings (scheduled and unscheduled) over the 1991:7-2015:10 period, columns (3) and (4) use only scheduled meetings over the 1994-2015:10 period. Column (5) focuses on LSAP shocks, all of which fall on scheduled meetings in the post-2008 period. Regression coefficients are standardized. $t$-statistics robust to heteroscedasticity are reported in parentheses. * $/ * * / * * *$ indicates significance at the $10 \% / 5 \% / 1 \%$ level. 


\begin{tabular}{|c|c|c|c|c|c|c|}
\hline \multicolumn{3}{|c|}{ A. Bond risk premium } & \multicolumn{4}{|c|}{ B. Equity risk premium } \\
\hline & (1) & $(2)$ & & (1) & $(2)$ & (3) \\
\hline & $\widehat{c f}$ (monthly) & CP (monthly) & & Martin (daily) & KP (monthly) & CAY (quarterly) \\
\hline \multirow[t]{2}{*}{$\omega^{g}$} & $0.302^{* * *}$ & $0.125^{* *}$ & $\omega^{g}$ & $-0.348^{* * *}$ & $-0.137^{* * *}$ & $-0.370^{* * *}$ \\
\hline & $(16.75)$ & $(2.23)$ & & $(-19.59)$ & $(-2.64)$ & $(-3.84)$ \\
\hline \multirow[t]{2}{*}{$\omega^{m}$} & $0.104^{* * *}$ & 0.001 & $\omega^{m}$ & $0.277 * * *$ & $0.197 * * *$ & $0.280 * * *$ \\
\hline & $(5.82)$ & $(0.03)$ & & $(18.07)$ & $(2.99)$ & $(3.51)$ \\
\hline \multirow[t]{2}{*}{$\omega^{p-}$} & $0.753^{* * *}$ & $0.551^{* * *}$ & $\omega^{p-}$ & $0.248 * * *$ & $0.122^{* *}$ & $0.186^{* *}$ \\
\hline & $(42.06)$ & $(10.69)$ & & $(14.55)$ & $(2.55)$ & $(2.51)$ \\
\hline \multirow[t]{2}{*}{$\omega^{p+}$} & $-0.467^{* * *}$ & $-0.404^{* * *}$ & $\omega^{p+}$ & $0.416^{* * *}$ & $0.181 * * *$ & 0.136 \\
\hline & $(-30.57)$ & $(-12.22)$ & & $(23.14)$ & $(3.09)$ & $(1.44)$ \\
\hline$R^{2}$ & 0.92 & 0.51 & $R^{2}$ & 0.56 & 0.081 & 0.21 \\
\hline$R^{2}\left(\omega^{p-}, \omega^{p+}\right)$ & 0.81 & 0.49 & $R^{2}\left(\omega^{p-}, \omega^{p+}\right)$ & 0.38 & 0.035 & 0.051 \\
\hline $\mathrm{N}$ & 419 & 419 & $\mathrm{~N}$ & 4051 & 336 & 138 \\
\hline
\end{tabular}

Table 3. Linking $\omega$ shocks with innovations to equity and bond risk premium proxies. The table reports regressions of innovations in different estimates of the bond and equity risk premium on $\omega$ shocks. Bond premium proxies (Panel A) are obtained following Cieslak and Povala $(2015, \widehat{c f})$ and Cochrane and Piazzesi (2005, CP). Equity premium proxies (Panel B) are the lower bound on the one-year equity premium from Martin (2017), the Kelly and Pruitt (2013, KP) measure, and the CAY variable from Lettau and Ludvigson (2001). Martin's estimates is available at a daily frequency; KP is available monthly, and CAY quarterly. The variables are obtained from respective authors' websites. Innovations to the risk premium proxies are computed as residuals from an AR process, where the number of lags is selected using the BIC. (The results are very similar if we use simple changes instead of AR residuals.) $\omega$ shocks are aggregated to monthly (quarterly) frequency by summing up daily shocks within each month (quarter). Regression coefficients are standardized. Regressions in Panel A are estimated over the 1983-2017 sample. In Panel B, Martin's premium is available for Jan 5, 1996-Jan 31, 2012. The KP data ends in Dec 2010, and CAY data ends in the 3rd quarter of 2017, both starting in 1983. For comparison with the four-shock regressions, the row labelled " $R^{2}\left(\omega^{p-}, \omega^{p+}\right)$ " reports the $R^{2}$ from regressions using only two risk-premium shocks, $\omega^{p-}, \omega^{p+}$. Robust $t$-statistics are reported in parentheses. $* / * * / * * *$ indicates significance at the $10 \% / 5 \% / 1 \%$ level. 